Федеральная служба по интеллектуальной собственности

(Роспатент)

Федеральное государственное бюджетное учреждение «Федеральный институт промышленной собственности»

(ФИПС)

ПРЕПРИНТ ПО МАТЕРИАЛАМ ОТЧЕТА

О НАУЧНО-ИССЛЕДОВАТЕЛЬСКОЙ РАБОТЕ ${ }^{1}$

\title{
ИССЛЕДОВАНИЕ ВОЗМОЖНОСТЕЙ КОМПЛЕКСНОГО ИСПОЛЬЗОВАНИЯ ЭЛЕКТРОННЫХ РЕСУРСОВ ВОИС В ОБЛАСТИ ПРОМЫШЛЕННЫХ ОБРАЗЦОВ И ПОДГОТОВКА НЕОБХОДИМЫХ РУКОВОДСТВ ДЛЯ РОССИЙСКИХ ПОЛЬЗОВАТЕЛЕЙ \\ (промежуточный)
}

Этап 1 Исследование основных средств поиска и электронных сервисов ВОИС, обеспечивающих делопроизводство по международным заявкам на регистрацию промышленных образцов

Подэтап 1.2 Исследование электронных сервисов ВОИС подачи заявки на международную регистрацию промышленных образцов, продления действия международной регистрации и оплаты пошлин в режиме онлайн

$$
\text { 2-ИТ-20221 }
$$

ФУНКЦИОНАЛЬНЫЕ ВОЗМОЖНОСТИ СЕРВИСОВ ВОИС «Е-НАGUЕ» , «ЕRENEWAL» И «Е-РАҮ» И ИХ ИСПОЛЬЗОВАНИЕ ПРИ ПОДАЧЕ ЗАЯВКИ НА МЕЖДУНАРОДНУЮ РЕГИСТРАЦИЮ ПРОМЫШЛЕННЫХ ОБРАЗЦОВ

Негуляев Г.А., Федяева И.А., Грачева Ю.Б.

Москва 2021

\footnotetext{
${ }^{1}$ НИР выполнена в рамках утвержденного государственного задания на 2021 год и на плановый период 2022 и 2023 годов №168-00001-21-00 от 29.12.2020
} 


\section{Аннотация}

Объектом исследования являются электронные ресурсы и сервисы ВОИС, предоставляемые пользователям Гаагской системы международной регистрации промышленных образцов, и возможности их комплексного использования российскими заявителями.

Целью НИР является повышение активности подачи заявок на международную регистрацию промышленных образцов отечественными заявителями за счет разработки методических пособий и Руководств пользователя, позволяющих более активно использовать электронные ресурсы и сервисы ВОИС.

В результате экспериментальных исследований процедур подачи заявки на международную регистрацию промышленных образцов, продления действия международной регистрации и оплаты регистрационных пошлин и иных сборов в электронном виде с использованием цифрового сервиса ВОИС «еHague», включающего два функциональных блока: E-Filing (электронной подачи заявки) и ЕRenewal (онлайн - продления действия международной регистрации), а также исследования процедуры онлайн - оплаты пошлин и сборов с использованием электронного сервиса Е-Рау получены аналитические материалы, включающие описание пользовательских интерфейсов, состав полей и данных, необходимых для ввода, характеристики форматов записи, способы доступа и т.д. На основе полученных материалов планируется выпуск комплекса Руководств пользователя для русскоязычной аудитории заявителей, что может существенно повлиять на рост активности подачи ими заявок на международную регистрацию промышленных образцов. 


\section{Список исполнителей}

Журавлев А. Л. - научный руководитель НИР, начальник Центра международной кооперации, к.ю.н. ,ФИПС, $\underline{\text { AZhuravlev@rupto.ru }}$

Негуляев Г.А. - ответственный исполнитель, ведущий научный сотрудник отдела международных классификаций и информационной поддержки поиска в области объектов патентного права, ФИПС, GNegouliaev@rupto.ru

Бородай Л.Н. - заведующий отделом международных регистрационных систем, ФИПС, larisa.boroday@rupto.ru

Дарина О.Н. - старший научный сотрудник отдела международных классификаций и информационной поддержки поиска в области объектов патентного права, ФИПС, otd3226@rupto.ru

Федяева И.А. - старший научный сотрудник отдела международных классификаций и информационной поддержки поиска в области объектов патентного права, ФИПС, otd3218@rupto.ru

Грачева Ю.Б. - государственный эксперт 1-й категории отдела международных регистрационных систем, ФИПС, otd11309@rupto.ru

Хинский С.Н.. - научный сотрудник отдела международных классификаций и информационной поддержки поиска в области объектов патентного права, ФИПС, otd3230@rupto.ru 


\section{Содержание}

Перечень сокращений и обозначений.................................... 5

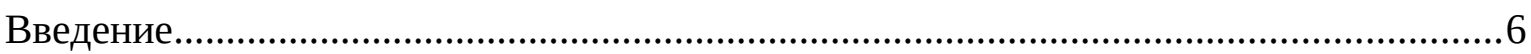

1. Общая характеристика процедуры международной регистрации промышленных

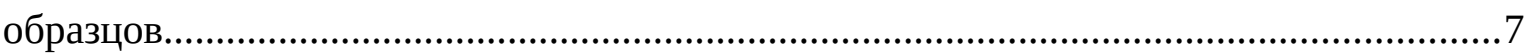

1.1. Процедурные требования к подаче международной заявки................................7

1.2. Требования к содержанию международной заявки...........................................8

1.3. Продление действия международной регистрации промышленных

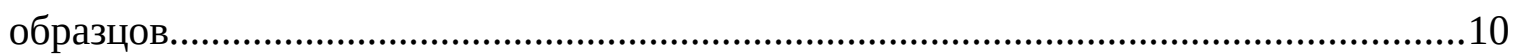

1.4. Пошлины, уплачиваемые в отношении международной заявки......................10

2. Анализ статистических данных об использовании Гаагской системы....................11

3. Электронные сервисы ВОИС для Гаагской системы международной регистрации

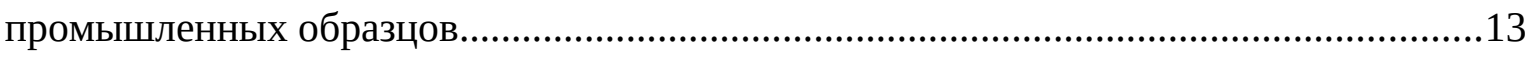

3.1. Общая характеристика системы еНаgue.............................................................14

3.2. Способы доступа к системе eHague.....................................................................15

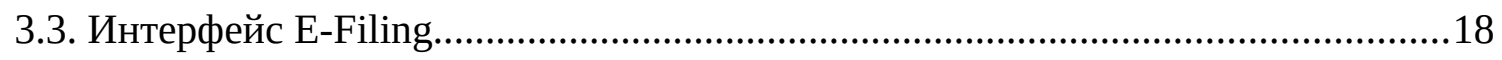

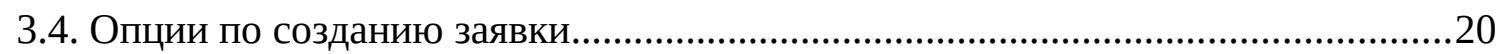

3.5. Вкладка «Filed application(s) » - (Поданные заявки........................ 32

3.6. Вкладка «Draft application(s)» - (Черновики заявок) .............................33

3.7. Вкладка «еHague Communication» - (Коммуникации) .........................34

4. Пользовательский сервис для продления действия международных

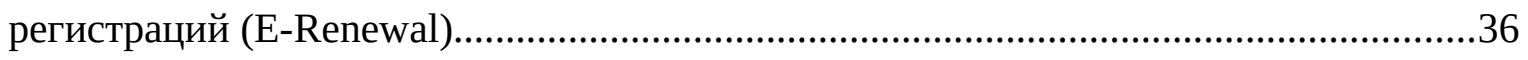

5. Сервисы ВОИС онлайн - оплаты пошлин................................................................37

5.1. Оплата регистрационных пошлин с использованием сервиса «еHague»...........37

5.2. Оплата с текущего счета ВОИС (Current Account at WIPO)...............................38

5.3. Оплата кредитной картой........................................ 40

5.4. Оплата банковским переводом......................................... 42

5.5. Оплата с использованием международной дебетовой электронной платежной системы PayPal.................................................... 43

5.6. Сервис ВОИС онлайн - оплаты пошлин Е-Рау...................................................44

5.7.Онлайн - оплата продления срока действия международных

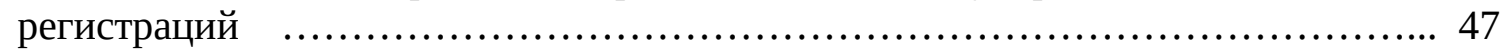

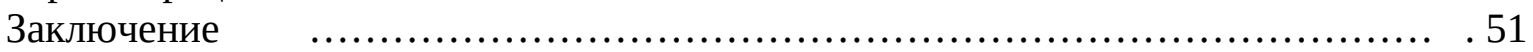

Список использованных источников .................................... 52 


\section{Перечень сокращений и обозначений}

В настоящей работе применяют следующие термины с соответствующими определениями.

МБ ВОИС

Административная

Инструкция

Женевский акт

МКПО

Парижская

конвенция

ВОИС

Гаагская система

Договаривающаяся сторона

НИР
Международное бюро ВОИС

Административная Инструкция по применению Гаагского соглашения

Женевский акт 1999г. Гаагского соглашения о международной регистрации промышленных образцов

Международная классификация промышленных образцов

Конвенция по охране промышленной собственности

Всемирная организация интеллектуальной собственности

Гаагская система международной регистрации промышленных образцов

Сторона - участница Гаагского соглашения о международной регистрации промышленных образцов

Научно - исследовательская работа 


\section{Введение}

С присоединением Российской Федерации в 2018 году к Женевскому акту Гаагского соглашения о международной регистрации промышленных образцов для российских разработчиков дизайна появилась возможность осуществлять зарубежное патентование не только на основе национальных процедур, но с использованием международной процедуры, которая имеет ряд преимуществ. Процедура Гаагского соглашения дает возможность получения охраны промышленных образцов в различных Договаривающихся сторонах путем подачи одной международной заявки в МБ ВОИС. Международная заявка, по сути, заменяет серию национальных заявок, которые требовалось бы подавать в ведомства различных стран для получения охраны промышленных образцов на их территории. Международная заявка может включать до 100 промышленных образцов. При ее подаче не требуется прибегать к услугам патентных поверенных, а все необходимые пошлины уплачиваются в единой валюте - швейцарских франках.

Для удобства пользователей Гаагской системой международной регистрации промышленных образцов МБ ВОИС были разработаны электронные сервисы подачи заявок, продления действия международных регистраций, онлайн - оплаты пошлин, а также информационные ресурсы, содержащие сведения о международных регистрациях промышленных образцов и национальных регистрациях ряда стран участниц Гаагского соглашения. Электронные сервисы и ресурсы предоставлены пользователям в открытом доступе в сети Интернет на трех рабочих языках Гаагской системы: английском, французском и испанском. Отсутствие русскоязычных интерфейсов сервисов, предоставляемых ВОИС, затрудняет пользование ими для значительного числа российских заявителей, не владеющих в достаточной степени хотя бы одним из указанных языков. Задача по продвижению русского языка в качестве рабочего языка Гаагской системы поставлена. Однако для ее решения необходимо существенно увеличить активность подачи заявок на международную регистрацию промышленных образцов российскими заявителями, поскольку в настоящий момент количество подаваемых ими заявок значительно ниже количества заявок, подаваемых заявителями ряда других стран, чьи языки также не являются рабочими языками Гаагской системы, например, из Японии и Республики Корея.

Предполагается, что разработка русскоязычных Руководств пользователя, содержащих четкие инструкции в отношении данных, подлежащих включению в электронные формы заявки и различных ходатайств, а также комментарии процедурного и правового характера, может содействовать более активному использованию российскими заявителями электронных сервисов ВОИС, и, как следствие, увеличению числа подаваемых ими заявок на международную регистрацию. 


\section{1. Общая характеристика процедуры международной регистрации промышленных образцов}

\section{1. Процедурные требования к подаче международной заявки}

Для подачи международной заявки на регистрацию промышленного образца существует несколько альтернативных возможностей. Международная заявка может подаваться в Международное бюро на официальном бланке (бланк DM/1) на бумаге или в электронном виде с использованием интерфейса E-filing, доступного на сайте ВОИС. Заявки на бумаге могут направляться либо напрямую в МБ ВОИС, либо через Ведомство Договаривающейся стороны.

Международная заявка должна быть составлена на одном из трех рабочих языков Гаагской системы: - английском, французском или испанском. Вся последующая переписка по заявке с МБ ВОИС осуществляется либо на языке заявки, либо на указанном для переписки языке (чаще всего на английском).

Право на подачу международной заявки в соответствии с Женевским актом Гаагского соглашения [1] имеют заявители, которые удовлетворяют, по крайней мере, одному из следующих условий:

- является гражданином государства, являющегося Договаривающейся стороной, или государства-члена межправительственной организации, являющейся Договаривающейся стороной;

- имеет постоянное местожительство или обычное проживание на территории государства, являющегося Договаривающейся стороной, или на территории которого применяется договор, учреждающий межправительственную организацию, являющуюся Договаривающейся стороной;

- имеет действительное и не фиктивное промышленное или торговое предприятие на территории государства, являющегося Договаривающейся стороной, или на территории которого применяется договор, учреждающий межправительственную организацию, являющуюся Договаривающейся стороной;

Заявка на международную регистрацию промышленного образца может быть подана без предварительной подачи национальной заявки, при этом страна происхождения может быть указана наряду с другими указанными Договаривающимися сторонами, на территории которых испрашивается охрана, [1]

МБ ВОИС проверяет заявку на соответствие предписанным формальным требованиям. Сведения о международной заявке, отвечающей предписанным формальным требованиям, вносятся в Международный реестр. В предписанные сроки производится публикация сведений о международной регистрации промышленных образцов в Бюллетене международных образцов (International 
Designs Bulletin) [2].

Стандартная публикация производится через шесть месяцев с даты подачи международной заявки. По ходатайству заявителя может быть произведена ускоренная или отсроченная, на срок не более 30 месяцев с даты подачи заявки, публикация.

\section{2. Требования к содержанию международной заявки}

Требования к содержанию международной заявки подразделяются на три категории: обязательное содержание, дополнительное обязательное содержание при указании определенных Договаривающихся сторон и факультативное содержание, заполняемое по усмотрению заявителя.

K обязательному содержанию относится информация, которая должна содержаться в каждой международной заявке или сопровождать ее. Это предписанные сведения о заявителе, изображения образцов, для которых испрашивается охрана, и указание Договаривающихся сторон, на территории которых испрашивается охрана промышленных образцов и указание Договаривающейся стороны заявителя [1] .

Дополнительное обязательное содержание международной заявки состоит из элементов, уведомление о которых было сделано Договаривающейся стороной, и которые должны быть включены в международную заявку, если в ней содержится указание такой Договаривающейся стороны.

Дополнительные обязательные элементы, необходимые для целей установления даты подачи согласно положениям национального законодательства некоторых указанных Договаривающихся сторон, на территории которых испрашивается правовая охрана промышленных образцов. К числу дополнительных элементов относится: информация, касающаяся личности автора, краткое описание изображения или существенных признаков промышленного образца, в отношении которого подается заявка, и притязание согласно формулировке, приведенной Договаривающейся стороной в заявлении, поданном в МБ ВОИС.

Также к элементам дополнительного обязательного содержания международной заявки относятся клятва и/или заявление автора, если указанная в заявке Договаривающаяся сторона уведомила МБ ВОИС о том, что заявка должна быть подана от имени автора, и должен быть приложен тот или другой из указанных элементов.

Если в качестве автора указывается лицо, иное, чем лицо, названное в качестве заявителя, заявка должна сопровождаться заявлением о переуступке прав на нее лицом, указанным в качестве автора, лицу, названному в качестве заявителя. 
Факультативные элементы заявки - это элементы, отсутствие которых не служит основанием для признания международной заявки неправильно оформленной. Такие элементы могут быть включены в международную заявку по выбору заявителя.

Так в случаях, когда для указания какой-либо Договаривающейся стороны, представление сведений о личности автора или краткого описания не требуется, заявитель, тем не менее, может их включить.

Если заявитель хочет воспользоваться приоритетом предшествующей заявки в соответствии со статьей 4 Парижской конвенции [3], то в международной заявке должно содержаться заявление, претендующее на приоритет этой предшествующей заявки, вместе с указанием названия Ведомства, в которое была подана такая заявка, даты подачи и номера этой заявки.

Если заявитель захочет воспользоваться правом выставочного приоритета согласно статье 11 Парижской конвенции, то в международной заявке должно содержаться заявление о том, что изделие или изделия, которые составляют промышленный образец, экспонировались на официальной или официально признанной международной выставке, вместе с указанием места проведения этой выставки и даты.

Если заявитель хочет отсрочить публикацию сведений о промышленном образце, то в международной заявке должно содержаться ходатайство об отсрочке публикации [4] .

С присоединением к Гаагскому соглашению Японии, Республики Корея и США в Административную Инструкцию [5] были внесены дополнения в список факультативных элементов, которые могут быть включены в содержание международной заявки, для учета требований национального законодательства этих стран:

- в заявке должно содержаться заявление об исключении в отношении недостаточности новизны с указанием тех промышленных образцов, к которым это заявление относится, если заявитель желает получить льготу по новизне, что может предусматриваться законодательством указанной Договаривающейся стороны;

- заявка должна содержать заявление с указанием экономического статуса или притязание на него, дающие заявителю право на снижение пошлины, если заявитель желает получить снижение индивидуальной пошлины за указание;

- при указании в заявке Японии и/или Республики Корея заявитель может воспользоваться положением о связанных образцах, указав в ходатайстве какой из промышленных образцов или все промышленные образцы, содержащиеся в международной заявке, следует рассматривать во взаимосвязи с промышленным образцом, содержащимся в национальной или международной заявке или регистрации (главный промышленный образец). 


\section{3. Продление действия международной регистрации промышленных образцов}

Международная регистрация имеет первоначально действие в течение пятилетнего периода и может быть продлена на два дополнительных пятилетних периода. С учетом продления срок охраны в каждой Договаривающейся Стороне, указанной в соответствии с Женевским актом [3], составляет не менее 15 лет, начиная от даты международной регистрации.

В тех случаях, когда законодательство указанной Договаривающейся стороны предусматривает срок охраны, превышающий 15 лет, продление международной регистрации может осуществляться на срок, предусмотренный законодательством этой Договаривающейся стороны.

Продление международной регистрации может производиться в отношении всех или отдельных указанных Договаривающихся сторон, а также в отношении всех или отдельных промышленных образцов, являющихся объектом международной регистрации.

За шесть месяцев до истечения пятилетнего срока действия Международное бюро направляет владельцу и представителю, если таковой имеется, уведомление с указанием даты истечения срока действия международной регистрации. Факт неполучения указанного уведомления не является оправданием несоблюдения сроков [4].

Международная регистрация продлевается при условии уплаты предписанных пошлин.

\section{4. Пошлины, уплачиваемые в отношении международной заявки}

Пошлины подлежат уплате во время подачи международной заявки за исключением пошлины за публикацию, которая может быть уплачена позже, если в международной заявке содержится ходатайство об отсрочке публикации.

Индивидуальная пошлина за указание, подлежащая уплате в отношении соответствующей Договаривающейся стороны, например, при указании США, может состоять из двух частей.

Первая часть подлежит уплате во время подачи международной заявки, а вторая - в более позднюю дату, которая устанавливается в соответствии с законодательством соответствующей Договаривающейся стороны.

Вторая часть индивидуальной пошлины за указание может, по выбору владельца, быть уплачена непосредственно соответствующему Ведомству, либо через МБ ВОИС [4]. 
При продлении действия международной регистрации оплачиваются следующие пошлины: основная пошлина; стандартная или индивидуальная пошлина за указание в отношении каждой Договаривающейся стороны, в отношении которой должна продлеваться международная регистрация.

Уплата пошлин за продление производится самое позднее в дату, в которую должно быть осуществлено продление международной регистрации. Однако она может быть произведена и в течение шести месяцев с даты, в которую должно быть осуществлено продление международной регистрации, при условии, что одновременно с этим уплачивается дополнительный сбор, указанный в Перечне пошлин и сборов.

Международная регистрация не может быть продлена в отношении любой указанной Договаривающейся стороны, в отношении которой была произведена запись о недействительности применительно ко всем промышленным образцам. Международная регистрация также не может быть продлена в отношении любой указанной Договаривающейся стороны применительно к тем промышленным образцам, в отношении которых была произведена запись о недействительности в этой Договаривающейся стороне или запись об ограничении действия международной регистрации [4].

Все платежи, производимые Международному бюро, вносятся в швейцарской валюте. Ведомство, которое берет на себя сбор и пересылку пошлин, может принимать оплату от заявителя в другой валюте, но платежи, производимые Ведомством Международному бюро, должны вноситься в швейцарской валюте.

\section{2. Анализ статистических данных об использовании Гаагской системы международной регистрации}

В настоящее время заявители, использующие процедуру Гаагского соглашения, имеют возможность получения охраны промышленных образцов в 75 Договаривающихся сторонах, охватывающих 92 страну.

В ходе НИР была проанализирована динамика подачи международных заявок и количество промышленных образцов, содержащихся в международных заявках, за период с 2018 года (года присоединения РФ к Женевскому акту) по октябрь 2021 года, что дает наиболее полное представление об использовании Гаагской системы международной регистрации. Анализ проводился на основе данных WIPO IP Statistics Data Center [6]. В таблице приведены статистические данные общей динамики использования Гаагской системы и динамика ее использования российскими заявителями. 
Несмотря на ежегодный прирост количества подаваемых российскими заявителями заявок на международную регистрацию промышленных образцов (в 2020 г. увеличение составило 54\% по отношению к предыдущему году) доля их в общем количестве заявок, поданных в рамках Гаагской системы, составляет менее 1\% (0,56\% - в 2018 г., 0,98\% - в 2020 г.). По данным, приведенным в ежегодном обзоре ВОИС Hague Yearly 2021 [7], в рейтинге по количеству поданных в 2020 г. международных заявок Российская Федерация занимает 18 место. Российскими заявителями было подано заявок меньше в 20 раз, чем заявителями Республики Корея (1145 заявок - 1 место), в 9 раз, чем заявителями США (526 заявок - 4 место) и в 7 раз, чем заявителями Японии (408 заявок - 5 место). Доля российских промышленных образцов от общего количества образцов, содержащихся в международных заявках, составляет менее $1 \%(0,5 \%$ в 2018 г. $-0,6 \%$ в 2020 г.).

Таблица

Динамика использования Гаагской системы

\begin{tabular}{|c|c|c|c|c|}
\hline Годы & 2018 & 2019 & 2020 & $\begin{array}{l}2021 \\
\text { (за } 10 \text { мес.) }\end{array}$ \\
\hline $\begin{array}{l}\text { Общее количество заявок } \\
\text { международную регистрацию ПО }\end{array}$ & 5451 & 5894 & 5799 & 4301 \\
\hline $\begin{array}{l}\text { Общее } \quad \text { количество } \\
\text { содержащихся в МЗ }\end{array}$ & 19767 & 21857 & 18636 & 14497 \\
\hline $\begin{array}{l}\begin{array}{l}\text { Количество } \\
\text { заявителей }\end{array} \\
\end{array}$ & 31 & 37 & 57 & 43 \\
\hline $\begin{array}{lrrr}\text { Количество ПО в } & \text { МЗ } & \text { от } \\
\text { российских заявителей } & & \end{array}$ & 105 & 160 & 113 & 62 \\
\hline $\begin{array}{lr}\text { Количество } \mathrm{M3,} & \begin{array}{l}\text { поданных } \\
\text { российскими }\end{array} \\
\text { напрямую/ через Роспатент }\end{array}$ & $27 / 4$ & $23 / 14$ & $42 / 15$ & $37 / 6$ \\
\hline $\begin{array}{l}\text { Количество М3, поданных через } \\
\text { Роспатент с использованием } \\
\text { электронного сервиса подачи на } \\
\text { сайте ФИПС }\end{array}$ & - & 5 & 12 & - \\
\hline
\end{tabular}

Количество промышленных образцов, заявленных российскими дизайнерами на международную регистрацию, меньше в 19 раз, чем заявителями США, в 14 и 8 раз, чем заявителями Республики Корея и Японии, соответственно. На рисунке 1 
представлены страны, занимающие первые 20 мест в рейтинге по количеству поданных на регистрацию промышленных образцов.

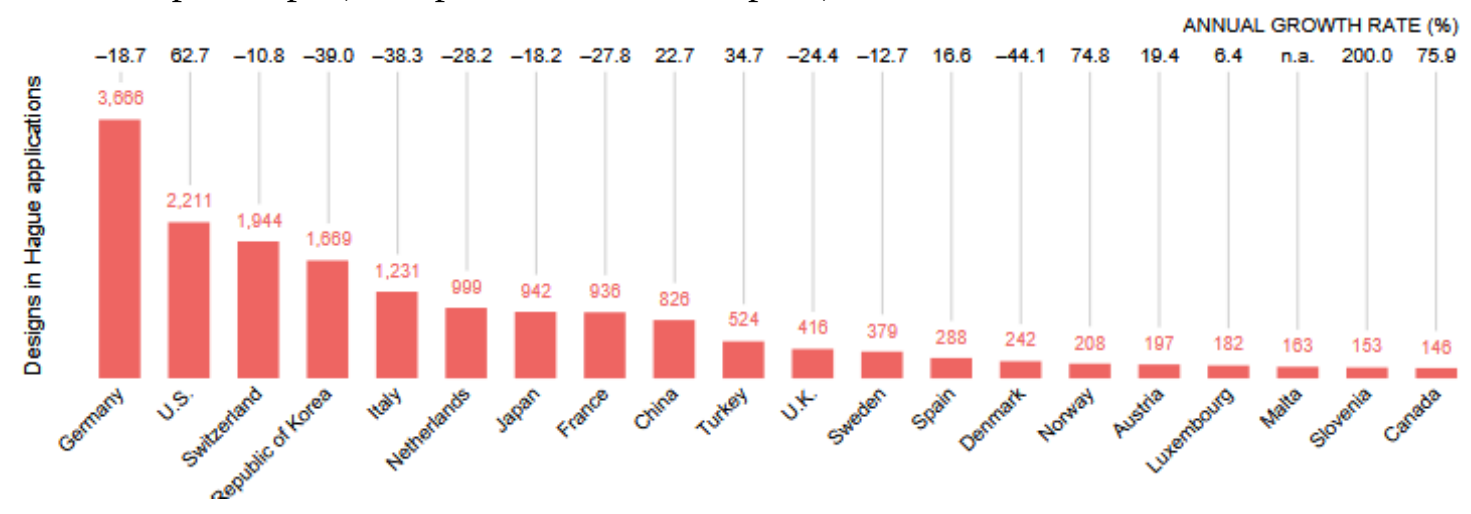

Рисунок 1 - Рейтинг стран по количеству промышленных образцов, содержащихся в международных заявках, поданных заявителями в 2020 году.

Рейтинг России по этому показателю ниже двадцатого места, как следует из представленных ВОИС данных о количестве промышленных образцов, содержащихся в международных заявках, поданных в 2020 году заявителями стран участниц Гаагского соглашения [7] (см. рис.1).

Проведенный анализ показал, что, несмотря на все преимущества Гаагской процедуры, ее использование российскими заявителями для получения охраны промышленных образцов за рубежом пока еще на достаточно низком уровне.

\section{3. Электронные сервисы ВОИС для Гаагской системы международной регистрации промышленных образцов}

Наиболее удобной и менее затратной является электронная подача международной заявки.

По данным ВОИС электронная подача заявок составила в 2020 г. 99,4\% от общего числа поданных заявок [7].

С помощью электронных сервисов ВОИС можно подать заявку на международную регистрацию, оплатить пошлины и иные сборы и продлить действие международной регистрации.

Электронная система на сайте ВОИС eHague позволяет выполнять все связанные с подачей заявки действия. Можно сохранить в системе заявку, чтобы заполнить и подать ее позднее, можно просматривать и скачивать свои заявки, можно отвечать на сообщения МБ ВОИС, а также можно легко производить оплату пошлин и иных сборов в режиме онлайн. 
Ниже представлены результаты исследования возможных вариантов доступа пользователей к сервису еНаgue и его функциональные возможности.

\section{1. Общая характеристика системы еHague}

Система eHague включает два функциональных блока: E-Filing, предназначенный для подачи заявки на международную регистрацию промышленных образцов, и E-Renewal, предназначенный для продления действия международной регистрации в режиме онлайн.

Интерфейс E-Filing позволяет:

- осуществлять подготовку международной заявки в электронном виде на английском, французском или испанском языке, с возможностью автоматизированной проверки правильности ввода контента в режиме реального времени, и отправлять ее в МБ ВОИС;

- сохранять и просматривать поданные заявки и не отправленные в МБ ВОИС заявки - черновики;

- редактировать не отправленные в МБ ВОИС заявки-черновики;

- оплачивать в режиме онлайн регистрационные пошлины за подачу международной заявки;

- получать в автоматизированном режиме уведомления от МБ ВОИС о зачете оплаченных пошлин и о наличии неоплаченных услуг ВОИС, касающихся подачи международной заявки, а так же другие уведомления, относящиеся к заявке;

- загружать в систему ряд документов (доверенность при назначении представителя, заявление (клятва) об авторстве, заявление о раскрытии информации и документы, подтверждающие право на получение льготы по новизне, документы, подтверждающие статус малого или микро- предприятия, для получения скидки по оплате пошлин, приоритетные документы и др.), необходимых при указании некоторых Договаривающихся сторон.

- перейти к Руководству, описывающему все этапы, связанные с подачей заявки на международную регистрацию промышленного образца с использованием интерфейса E-Filing, а также получить возможность доступа к демо-версии «еHagua» для создания тестовой версии международной заявки.

Выполнение данных функций в интерфейсе «E-Filing» осуществляется через следующие вкладки:

- «New»- вкладка для создания новой заявки «с нуля»;

- «Filed application(s)» - вкладка «поданные заявки» предназначена для просмотра поданных заявок;

- «Draft application(s)» - вкладка «черновики», в которой сохраняются черновики заявок с возможностью их редактирования в дальнейшем; 
- «eHague Communication» - вкладка «коммуникации» предназначена для получения уведомлений от МБ ВОИС в отношении международных заявок, поданных через интерфейс еНаguе, и ответа на них в режиме онлайн ;

- «eHague Tutorial» - вкладка «Руководство» предназначена для быстрого доступа к Руководству по электронной подаче заявки на международную регистрацию промышленных образцов, доступного пользователям на трех языках: английском, французском и испанском.

В зависимости от выбранной вкладки в открывшемся окне появляются, доступные для каждой из них, действия.

Вкладка «New» открыта по умолчанию при входе в систему eHague, поэтому для перехода в окно действий для создания новой заявки достаточно выбрать язык (английский, французский или испанский), на котором будет подаваться заявка, и нажать кнопку «confirm».

При подготовке новой международной заявки с использованием интерфейса «E-Filing» возможны следующие варианты:

- заявка создается впервые «с нуля», тогда в разделы, обязательные к заполнению для каждой заявки, необходимо вводить весь контент, предусмотренный данным разделом;

- заявка создается по шаблону ранее поданной заявителем заявки, тогда отдельные ранее введенные заявителем данные вводятся автоматически. Для создания заявки по шаблону можно выбрать как ранее поданную заявку из вкладки «Filed application(s)», так и заявку из вкладки «Draft application(s)»- черновики.

Международная заявка состоит из разделов. Чтобы развернуть раздел, следует нажать на название раздела на навигационной панели. В каждом разделе можно осуществлять различных действий, которые доступны с помощью кнопок действий, появляющихся перед областью ввода данных каждого раздела. Над кнопками действий и элементами строки раздела отображается информация, специфичная для данного раздела.

Система в автоматическом режиме отслеживает правильность заполнения разделов заявки. Если при заполнении раздела будет допущена ошибка, на экране интерфейса появляется сообщение об ошибке. Международная заявка не может быть подана, если не будут исправлены все ошибки.

\section{2. Способы доступа к системе еНаgue}

Пользоваться сервисами ВОИС могут только зарегистрированные пользователи, для чего необходимо создать аккаунт ВОИС (WIPO AKKOUNT). 
После получения подтверждения о создании аккаунта заявитель получает возможность доступа к системе еНаguе. Имеется несколько вариантов доступа к сервисам ВОИС. Перейти к сервису еНаguе можно:

- со страницы WIPO IP Portal сайта ВОИС;

- с Гаагской страницы сайта ВОИС.

На каждую из указанных страниц можно перейти главной страницы сайта ВОИС (адрес сайта: https://www.wipo.int/portal/en/index.html) по ссылкам WIPO IP Portal или Industrial Designs - WIPO HAGUE. Перейдя на главную страницу WIPO IP Portal, необходимо войти в свой аккаунт ВОИС путём щелчка по кнопке Login или по ссылке LOGIN в общем меню в верхней части страницы, при этом открывается страница входа в WIPO IP Portal , вид которой показан на рисунке 2.

\section{$\underset{\text { WPPO }}{\text { IPORTAL MENU }}$}

\section{WELCOME TO THE WIPO IP PORTAL}

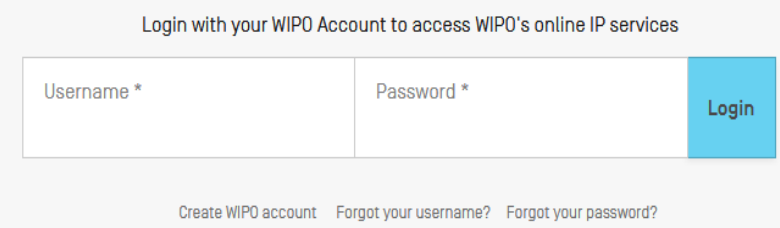

Рисунок 2 - Страница входа в WIPO IP Portal

После ввода логина и пароля и щелчка на кнопке Login на странице входа в WIPO IP Portal открывается страница MY DASHBOARD (см. рис.3), на которой имеются средства доступа к различным сервисам, предоставляемым WIPO IP Portal, называемые «виджетами» (widgets).

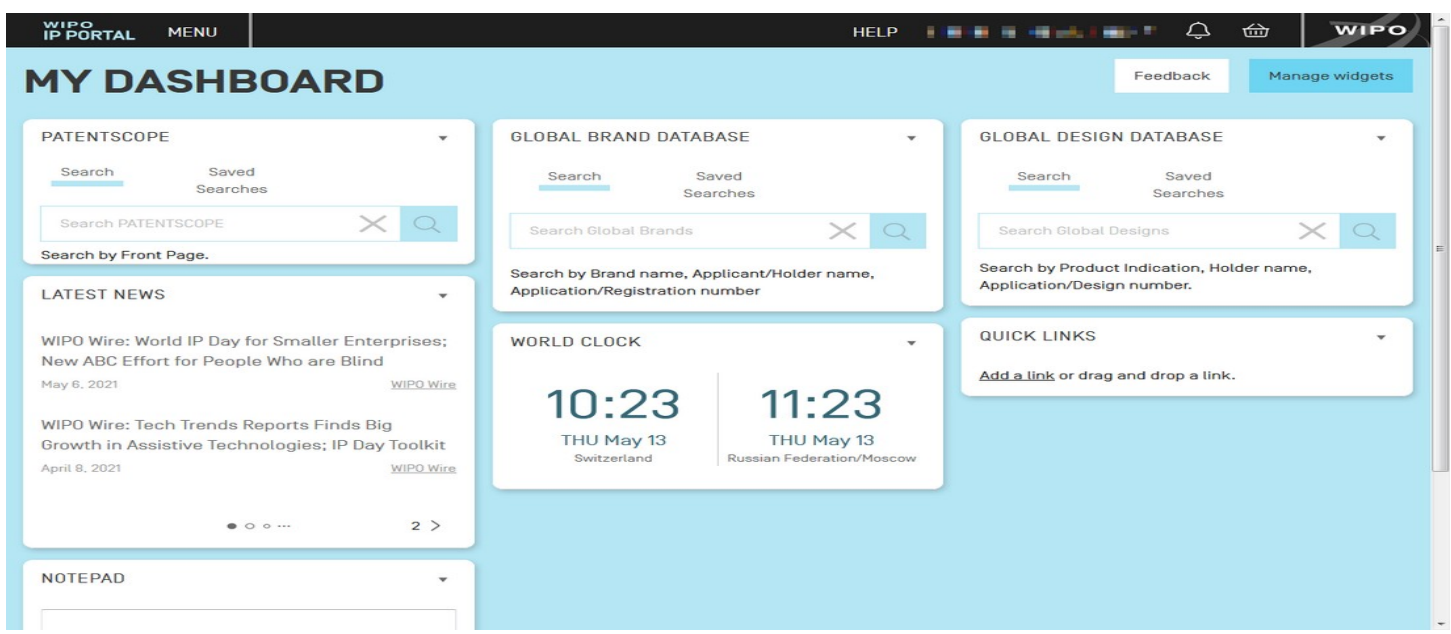

Рисунок 3 - Страница MY DASHBOARD 
Для доступа к сервису еHague, необходимо нажать ссылку MENU в общем меню в верхней части страницы. На открывшейся странице MENU выбрать кнопку DESIGNS, затем кнопку File and manage, после чего на экране появляется кнопка eHague (см. рис. 4).

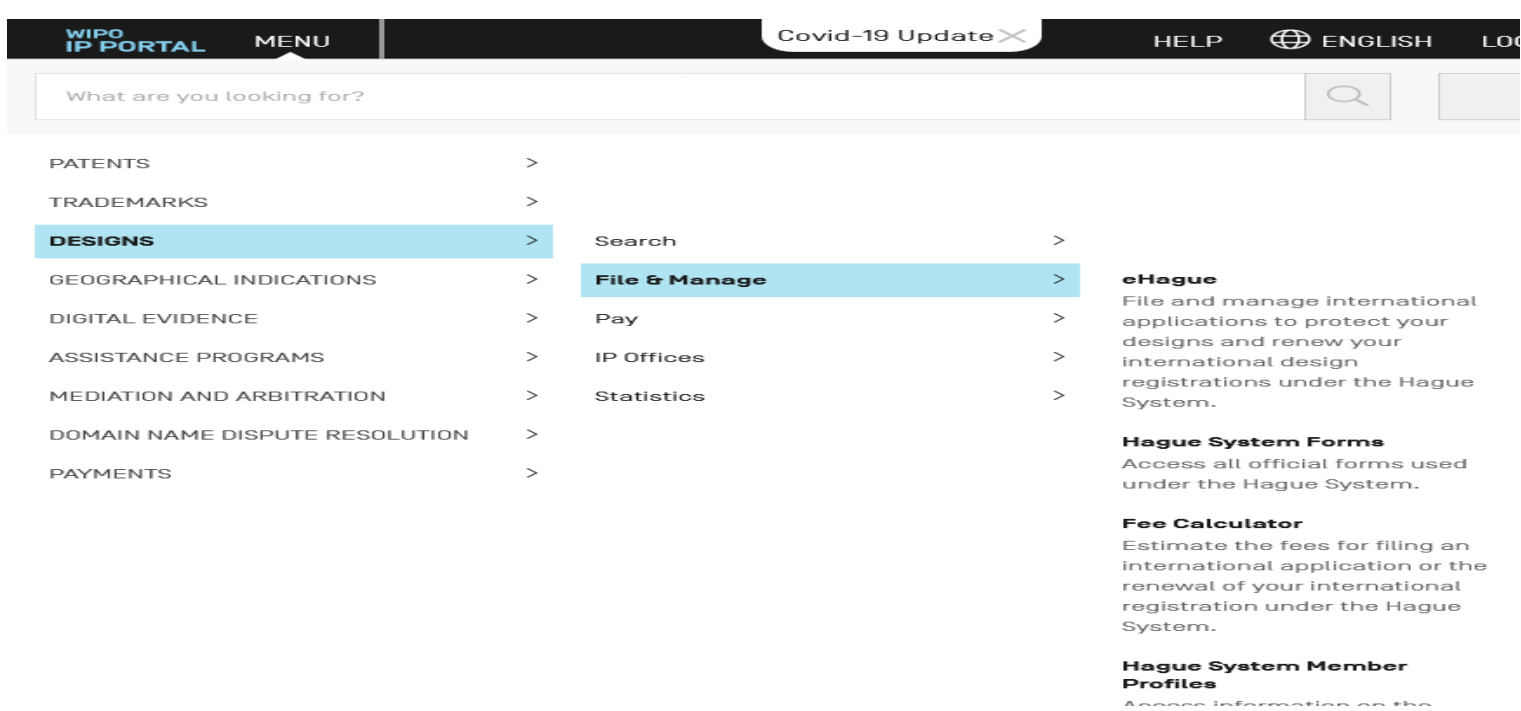

Рисунок 4 - Страница доступа к сервису еHague

После нажатия кнопки еHague попадаем на страницу сервиса, вид которой показан на рисунке 5. .

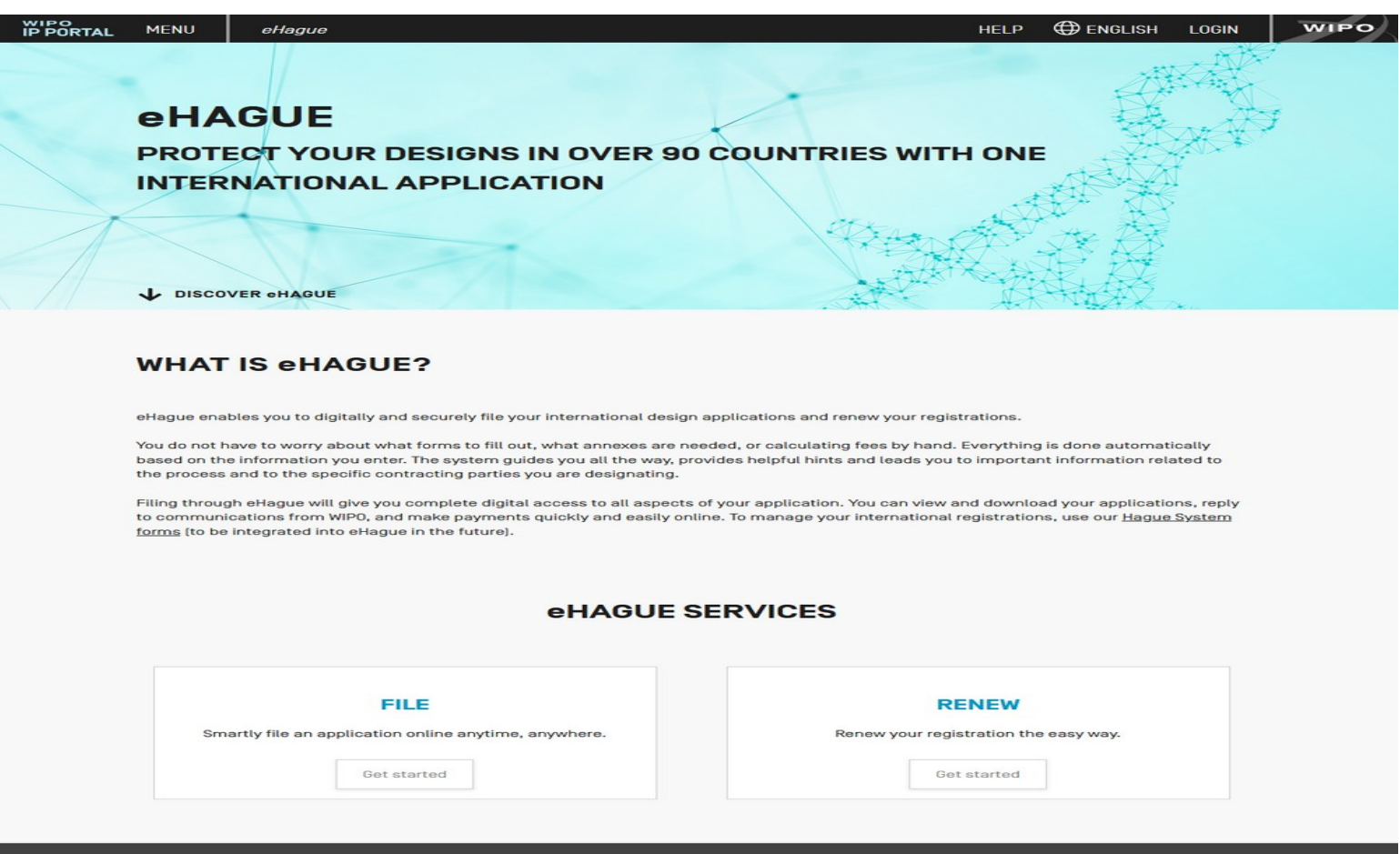

Рисунок 5 - Страница сервиса eHague 
Для перехода к начальной странице системы электронной подачи заявок необходимо щёлкнуть на кнопке Get started в разделе FILE системы eHague. Для продления действия международной регистрации - нажать аналогичную кнопку в разделе RENEW.

Также к сервису еHague можно перейти со страницы Hague - The International Design System (Гаагская международная система образцов) по ссылке eHague в разделе Resources (см. рис.6).

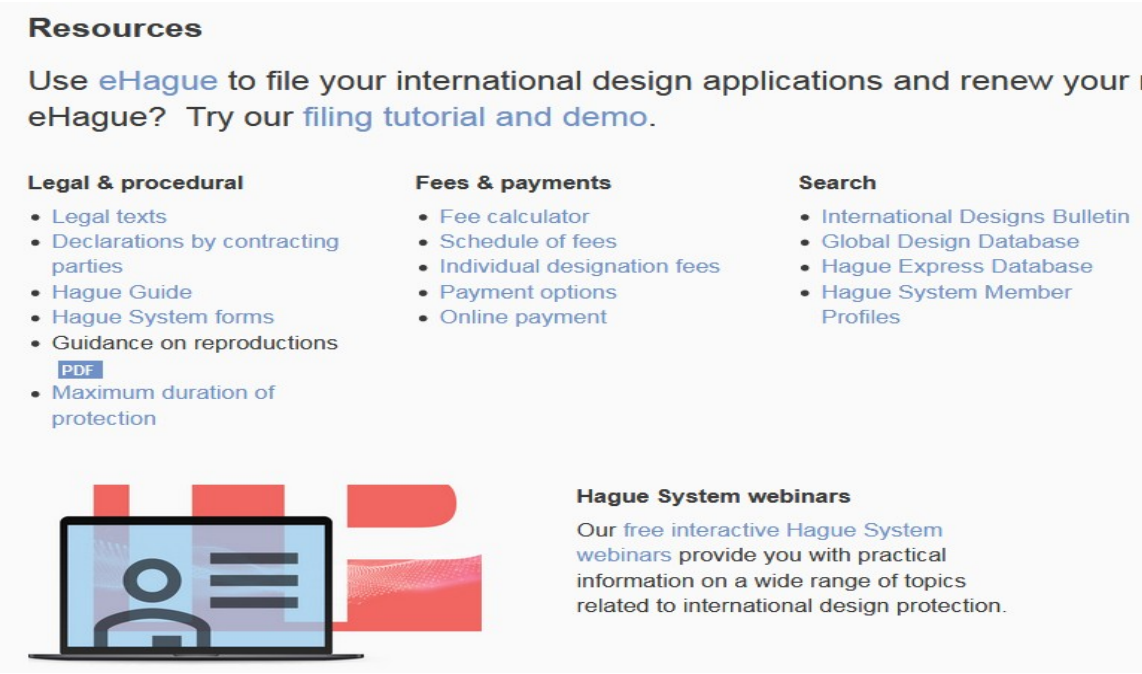

WIPO IP PORTAL

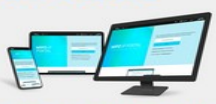

The one-stop shop for your online IP services

Рисунок 6 - Доступ к странице сервиса еHague со страницы Гаагская международная система образцов

\section{3. Интерфейс E-Filing}

Рабочий стол заявителя (E-FilingWorkbench) позволяет создавать новые заявки по Гаагской системе и управлять существующими заявками (отправленными и неотправленными). После регистрации международной заявки Workbench предназначен также для управления полным жизненным циклом международной регистрации от подачи до истечения срока действия.

Заявки автоматически сохраняются в режиме реального времени и всегда можно к ним вернуться и закончить позже.

Для перехода $\mathrm{K}$ начальной странице системы электронной подачи международных заявок на промышленные образцы необходимо нажать на кнопку Get started в разделе FILE на странице сервиса еHague (см. рис. 5). После ввода логина и пароля пользователя на открывшейся странице аккаунта, происходит переход на начальную страницу системы электронной подачи международных заявок на промышленные образцы, вид которой показан на рисунке 7. 


\section{EHAGUE}

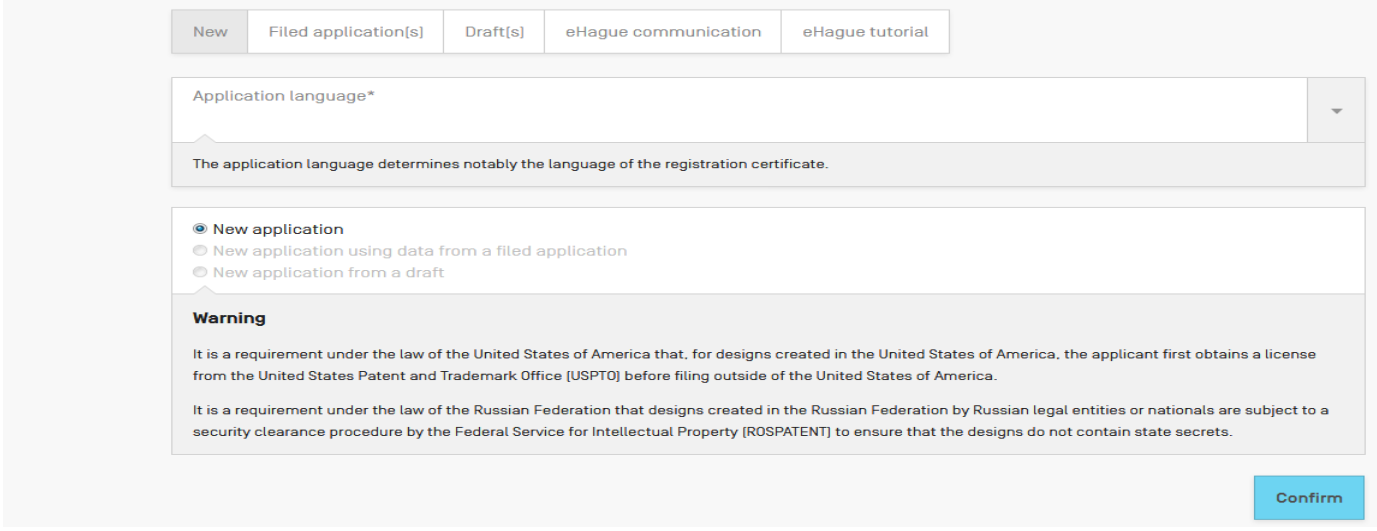

Рисунок 7 - Начальная страница сервиса электронной подачи заявок еHague

В верхней части страницы находится общее меню:

- WIPO IP PORTAL используется для перехода на страницу WIPO IP Portal;

- MENU, при щелчке на которое открывается список доступных сервисов, для всех видов интеллектуальной собственности, уплаты пошлин и др. (см. рис.4);

- eHague - используется для возвращения на главную страницу eHague из любого места в заявке;

- HELP (при щелчке на HELP открывается выпадающее подменю с пунктами: CONTACT US - для общения с Contact Hague service, FAQs - ответы на часто задаваемые вопросы по системе еHague (Hague System: eHague - Questions and Answers), TERMS OF USE и PRIVACY POLICY - условия пользования веб-сайтом и онлайновыми сервисами ВОИС и политика ВОИС по персональным данным и их конфиденциальность соответственно. Все страницы, доступные через пункт меню HELP, открываются в отдельной вкладке браузера);

- Имя пользователя, при щелчке на которое открывается выпадающее подменю с пунктами: MY WIPO ACCOUNT для изменений в аккаунте пользователя (имя пользователя, пароль, адрес электронной почты);

- Выбор языка интерфейса eHague - можно выбрать английский, испанский или французский язык;

LOGOUT - для выхода из заявки в любом её месте;

- Пиктограмма «колокольчик» $\triangle$, при щелчке на которую открывается выпадающее подменю с пунктами: GO TO ALL MESSAGES и OPEN MESSAGES IN NEW TAB, оба пункта меню дают доступ к централизованной системе сообщений сервисов WIPO IP, при этом пункт OPEN MESSAGES IN NEW TAB открывает страницу системы сообщений в отдельной вкладке браузера. 
- Пиктограмма «корзина» 向, при щелчке на которую открывается выпадающее подменю с пунктами: GO TO PAYMENT и OPEN PAYMENT IN NEW ТАВ, оба пункта меню дают доступ к странице платежей, на которой можно просмотреть сведения об оплатае различных действий, связанных с подачей заявок, при этом пункт OPEN PAYMENT IN NEW TAB открывает страницу платежей в отдельной вкладке браузера.

- WIPO используется для перехода на главную страницу сайта WIPO (открывается в отдельной вкладке браузера).

В верхней части главного диалогового окна расположены вкладки New, Filed application(s), Draft(s), eHague communication и eHague tutorial.

\section{4. Опции по созданию заявки}

При переходе на начальную страницу системы электронной подачи заявок eHague открыта вкладка New. При создании новой заявки, необходимо выбрать из выпадающего списка язык подачи заявки щелчком по полю Application language* (английский, французский и испанский см. рис. 8).

Также во вкладке New нужно выбрать одну из опций:

- New application (новая заявка) - подача новой заявки;

- New application using data from a filed application (новая заявка с использованием данных поданной заявки) - если была подана хотя бы одна заявка, при подаче заявки можно использовать данные ранее поданных заявок для экономии времени.

\begin{tabular}{ll|ll|l|l|}
\hline IIPPORTAL MENU & eHague & HELP & WIPO
\end{tabular}

\section{EHAGUE}

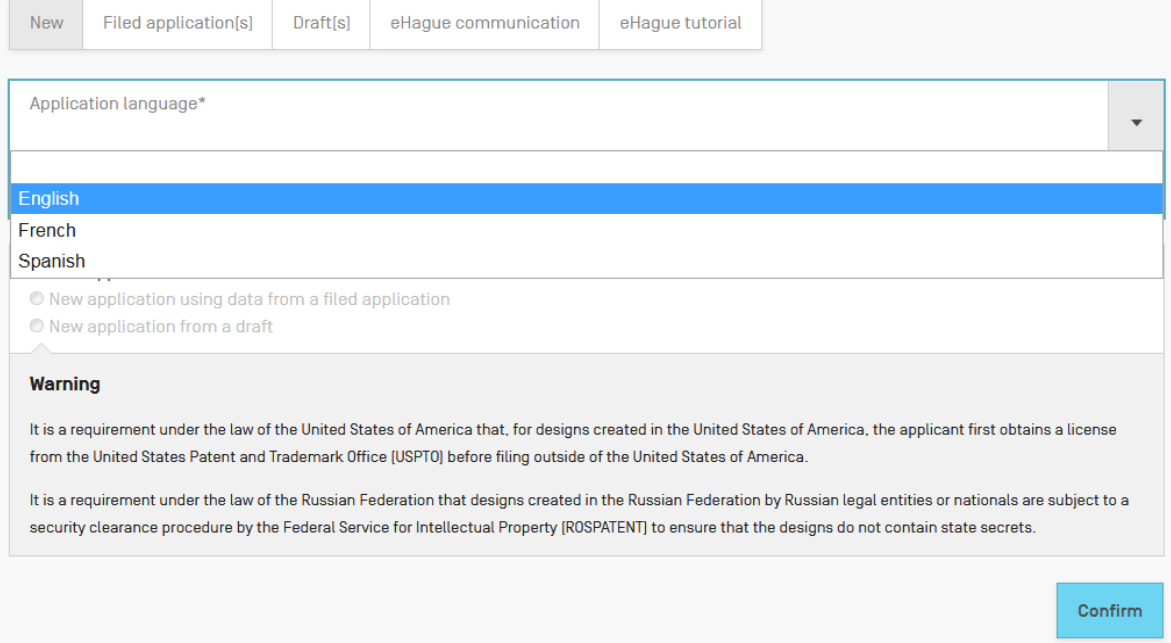

Рисунок 8 - Выбор языка подачи заявки на начальной странице системы электронной подачи заявок еHague 
Для выбора ранее поданной заявки необходимо щёлкнуть по полю Please select a reference No.* и в выпадающем списке выбрать номер заявки, данные которой желательно использовать. Для указания выбранных для использования данных из заявки их надо отметить в списке ниже поля выбора заявки (см. рис.9).

При подаче заявки можно также выбрать заявку из сохранённых незаконченных заявок для использования данных из нее в новой заявке -- New application from a draft (новая заявка из черновиков).

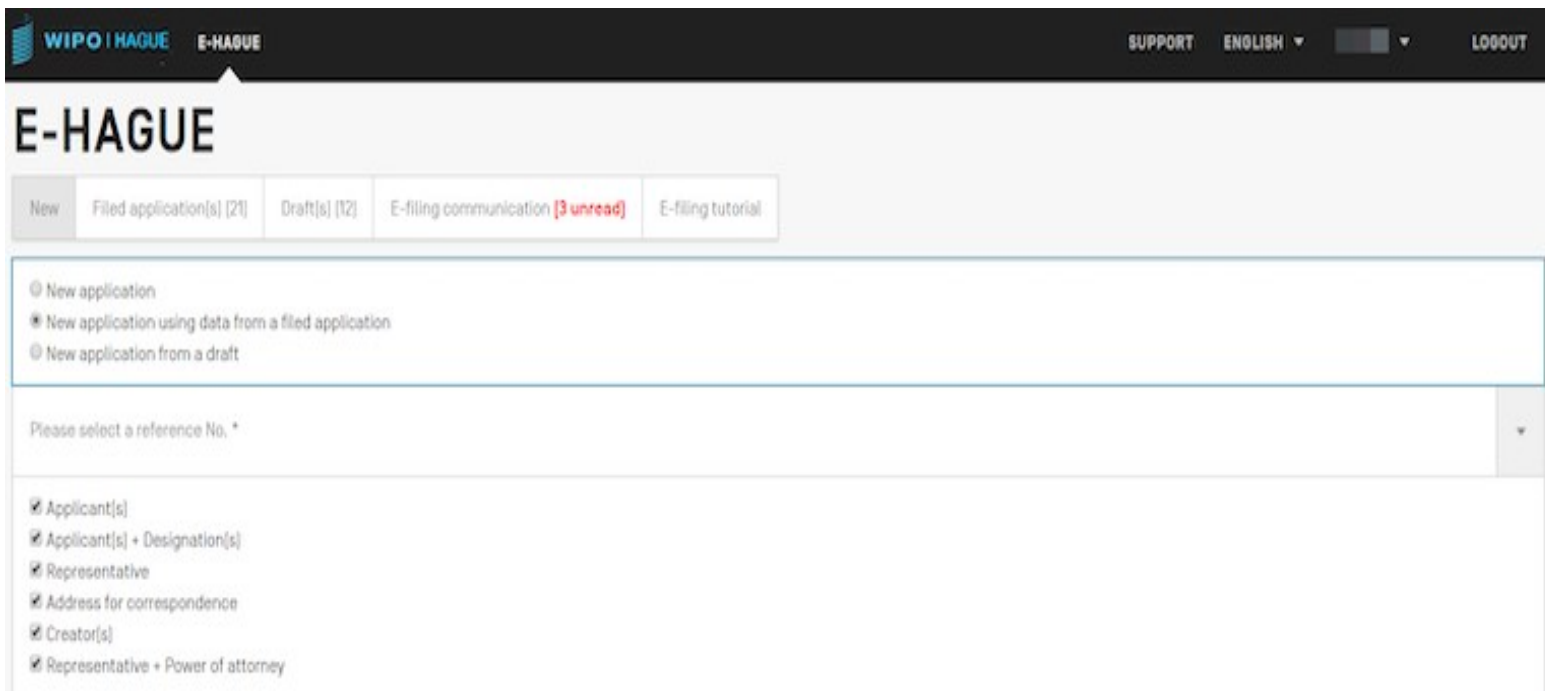

Рисунок 9 - Экран опции с использованием данных ранее поданной заявки

После указания языка и выбора ранее созданной заявки (при необходимости) для подтверждения и перехода по процедуре подачи заявки далее необходимо нажать на кнопку Confirm, при этом открывается раздел заявки, относящийся к указанию данных о заявителях (APPLICANT) (см. рис.10).

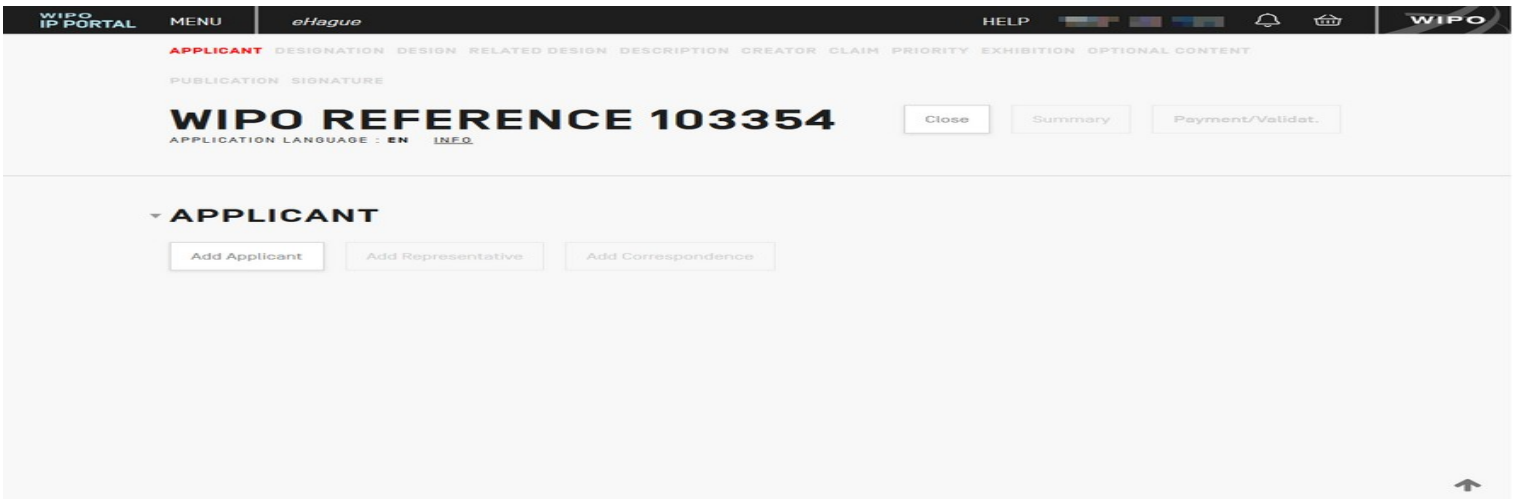

Рисунок 10 - Раздел международной заявки APPLICANT 
В этом разделе содержится ссылочный заявки, присвоенный ВОИС в системе электронной подачи и установленный язык подачи заявки.

В верхней части экрана имеется меню навигации по разделам заявки, позволяющее переходить к соответствующим разделам заявки щелчком по ним в любое время и из любого места заявки. Красным цветом выделяется ссылка, соответствующая незавершённому разделу, тёмно-серым цветом ссылки на разделы, которые можно редактировать, светло-серым цветом ссылки на разделы, которые нельзя редактировать.

Международная заявка состоит из следующих разделов, которые отображены на навигационной панели в верхней части экрана:

- Applicant - Заявитель;

- Designation - Указание (Договаривающихся сторон);

- Design - Дизайн (Промышленный образец);

- Related Design - Связанные образцы;

- Description - Описание;

- Creator - Автор (создатель);

- Claim - Притязания;

- Priority (optional) - Приоритет (факультативный);

- Exhibition (optional) - Выставочный приоритет (факультативный);

- Optional Content - Необязательный контент;

- Publication - Публикация;

- Signature - Подпись.

Не все разделы будут активированы для каждой заявки, поскольку заполнение некоторых разделов будет необходимым только при указании определенных Договаривающихся сторон.

Первые три раздела (Applicant, Designation, Design) являются обязательными для каждой заявки. Остальные разделы активируются только после того, как будут правильно заполнены эти три раздела заявки. Если при заполнении раздела будут допущены ошибки, система укажет на ошибки, выделив их красным цветом.

Не все разделы будут доступны для любой заявки, так как это зависит от специфики каждой заявки. Например, если заявка не содержит указанную страну, которая позволяет указать связанные образцы (Related Design), раздел Related Design будет нередактируемым и обозначаться светло-серым цветом ссылки.

Для просмотра содержимого раздела заявки его необходимо развернуть щелчком по пиктограмме пиктограмма изменится на $\nabla$.

Чтобы свернуть раздел необходимо щёлкнуть на пиктограмме $\nabla$, находящейся слева от названия раздела. 
На экране имеются функциональные кнопки: Add Applicant - для добавления сведений о заявителе, Close - для перехода к начальной странице системы электронной подачи заявок еНаgue. при наведении курсора на ссылку INFO открывается сообщение о том, что язык свидетельства о регистрации определяется языком подачи заявки, устанавливаемом при её оформлении.

При нажатии на кнопку Add Applicant открывается форма ввода сведений o заявителе (см. рис.11).

Обязательными для заполнения являются следующие поля раздела заявки «Applicant»:

- Given name, Family name - имя, фамилия (заявителя - физического лица);

- Name official designation - официальное название( заявителя - юридического лица);

- Street address -адрес;

- City -город;

- Country -страна;

- E-mail address - адрес электронной почты.

Затем, используя меню прокрутки вниз, необходимо указать хотя бы одно право для заявителя в одном из следующих полей:

- Nationalety - гражданство;

- Domiclle - место проживания;

- Real and effective industrial or commercial establishment - реальное и эффективное промышленное или коммерческое предприятие;

- Habitual residence - обычное место жительства.

Обязательные для заполнения поля отмечены звездочкой.

После заполнения раздела следует нажать кнопку «save» - (сохранить). Если раздел заполнен без ошибок, то можно перейти к заполнению следующего раздела заявки «Designation» - Указание Договаривающихся сторон. 
WIPO REFERENCE 104243

application language: en INFO

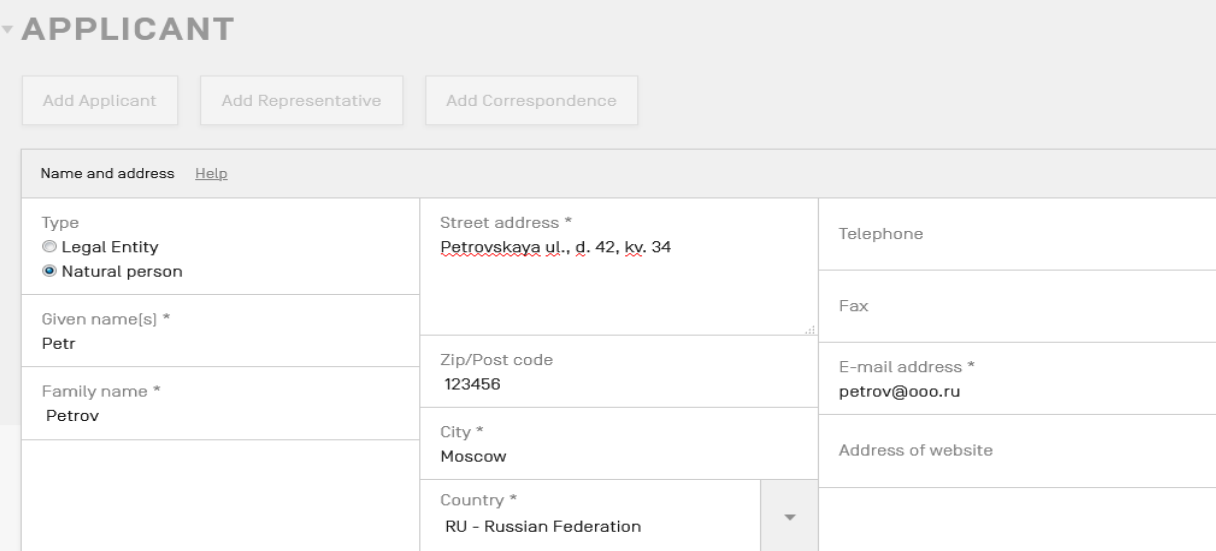

Entitlements Help

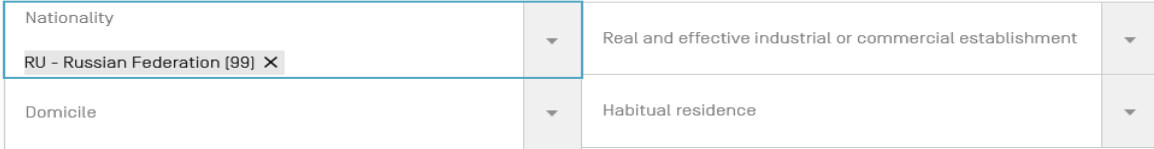

Applicant's Contracting Party [ACP] Help

Applicant's Contracting Party [ACP]

$\mathrm{RU}$ - Russian Federation [99

99

\section{DESIGNATION}

\section{DESIGN}

Рисунок 11 - Страница ввода сведений о заявителе

Если при заполнении были допущены ошибки, система отметит их красным цветом.

Раздел заявки «Designation» (см. рис. 12) предназначен для указания Договаривающихся сторон, на территории которых испрашивается охрана. 


\section{- DESIGNATION}

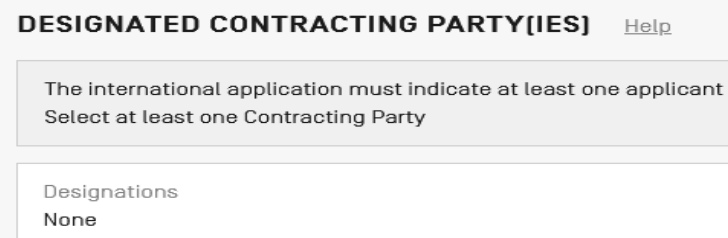

Рисунок 12 - Раздел заявки «Designation» («Указание Договаривающейся стороны»)

В верхней части окна содержится предупреждение о том, что в международной заявке обязательно должны быть указаны хотя бы один заявитель и хотя бы одна Договаривающаяся сторона.

При нажатии кнопки «change selection» появляется выпадающий отмечаютссписок Договаривающихся сторон, в котором отмечаются те, на территории которых испрашивается охрана. Для указания всех Договаривающихся сторон в верхней части окна расположена кнопка «Select all», для отмены указания кнопка «Deselect all». После того, как Договаривающиеся стороны будут в списке отмечены, следует нажать кнопку действий «Ok» и перейти к разделу «Design» -(« Дизайн»).

Раздел «Design» состоит из трех подразделов (см. рис. 13).

\section{DESIGN}

\begin{tabular}{l} 
INFORMATION CONCERNING DESIGN[S] Help \\
The international application must indicate at least one design \\
The reproductions are published in the color mode as originally submitted. \\
How toprepare your reproductions \\
\hline $\begin{array}{l}\text { Total number of design[s] } 0 \\
\text { Total number of reproduction[s] } 0\end{array}$ \\
Locarno Class \\
\hline Locarno Class \\
Not specified \\
\hline Add design
\end{tabular}

Рисунок 13 -Подраздел класса МКПО раздела «Design» 
В поле белого цвета с красной полосой, расположенном в верхней части окна, содержится предупреждение о том, что международная заявка должна содержать, по крайней мере, один промышленный образец. В сером поле, расположенным ниже, содержится информация о том, что изображения промышленных образцов будут опубликованы в том цветовом решении, в котором они были первоначально представлены. Так же в данном поле по гиперссылке «How to prepare your reproductions» можно перейти к Руководству по подготовке изображений.

Поле, предназначенное для отображения общего количества промышленных образцов и общего количества изображений, заполняется автоматически при заполнении двух следующих подразделов раздела «Design».

В подразделе для указания класса МКПО (Локарнской классификации), к которому относится изделие или изделия, представляющие промышленный образец, необходимо из выпадающего списка классов в поле «Locarno Class» выбирать нужный класс, после чего нажать на кнопку «Add design» - (Добавить дизайн) и перейти к следующему подразделу.

Следующий подраздел состоит из двух полей (см. рис. 14). Одно из полей предназначено для указания, путем выбора из выпадающего списка, подкласса Локарнской классификации, к которому относится заявляемый промышленный образец. Другое поле предназначено для указания изделия, в отношении которого заявлен промышленный образец, путем выбора из выпадающего списка изделий.

NEW DESIGN

Locarno Subclass

11 - Cycles and motorcycles

Product indication *

Bicycle

Рисунок 14 - Подраздел указания изделия раздела «Design»

В нижней части подраздела справа расположены две кнопки действий: «Save» - (Cохранить) и «Cancel» -(Отменить) (см. рис. 14). После выбора подкласса и указания изделия необходимо нажать кнопку «Save» и перейти к заполнению следующего подраздела, предназначенного для ввода изображений промышленных образцов (см. рис. 15) 


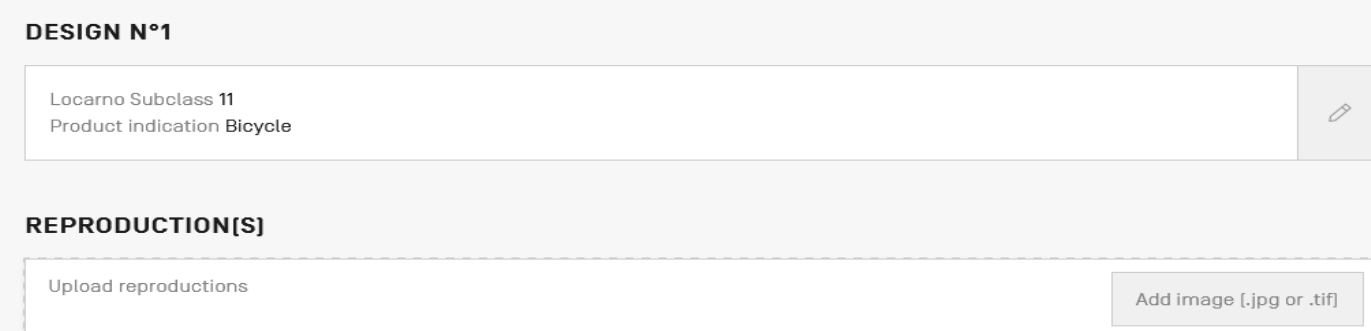

Рисунок 15 - Подраздел загрузки изображений

В поле для ввода изображений расположена кнопка действий «Add image [jpg or tif]» - (Добавить изображение). Загрузка изображений с персонального компьютера осуществляется при нажатии данной кнопки. Изображения могут быть загружены при условии, что они имеют формат «jpg» или «tif». После загрузки изображений необходимо нажать кнопку «Ok», после чего откроется сводное окно раздела «Design» (см. рис. 16).

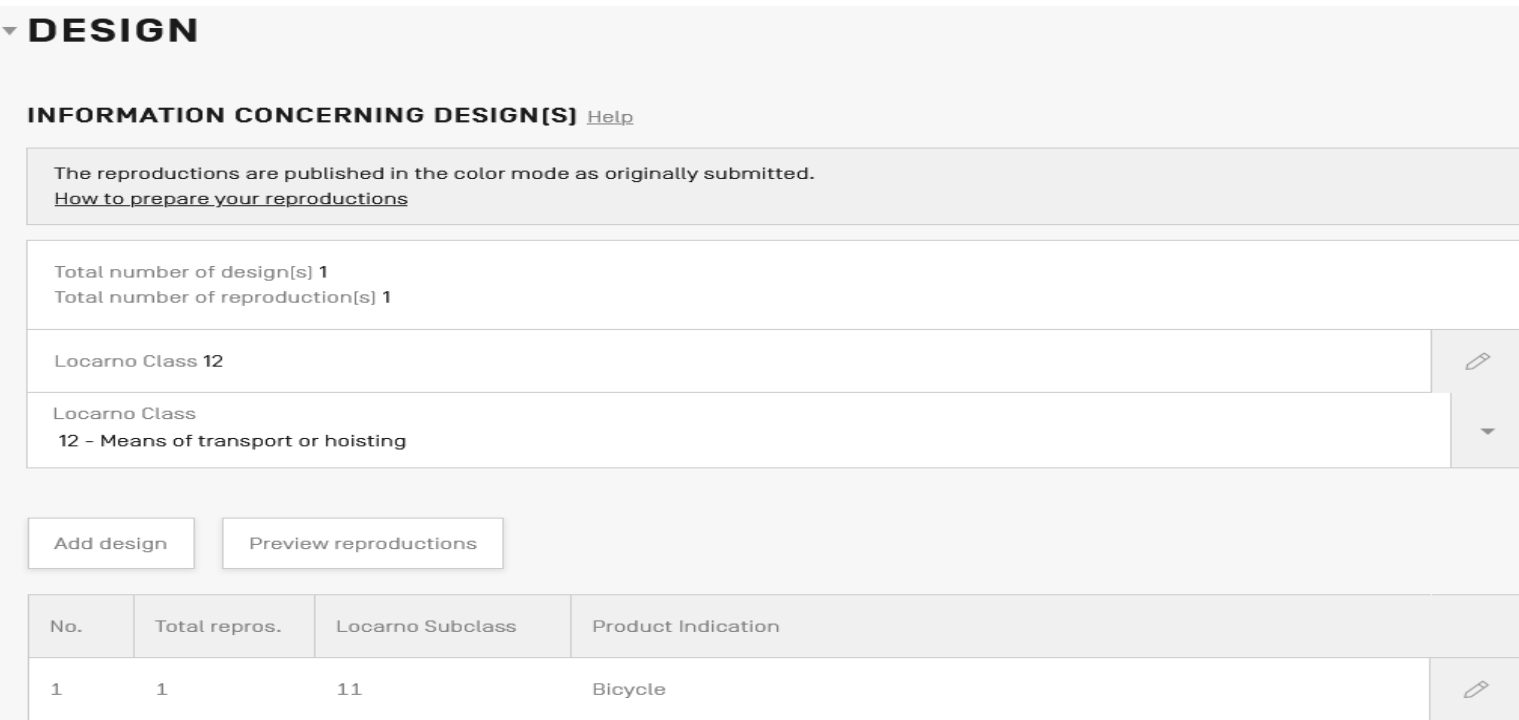

Рисунок 16 - Вид сводного окна раздела «Design»

В окне указывается общее количество введенных промышленных образцов, общее число загруженных изображений промышленного образца, класс Локарнской классификации, к которому относится заявленный образец и изделие, в отношении которого заявлен образец.

Функциональная кнопка действий «Preview reproduction» - «Предварительный просмотр изображений» позволяет увидеть, как будет выглядеть загруженное изображение в напечатанном виде. 
После того, как для каждого заявленного промышленного образца будет загружено хотя бы одно изображение, в меню навигации станут доступными другие разделы заявки, появится возможность перемещаться по разделам заявки для их заполнения по мере необходимости, поскольку заполнение ряда разделов не является обязательным для каждой заявки.

К числу обязательных разделов также относятся разделы «Publication»(Публикация) и «Signature» - (Подпись).

На рисунке 17 показано окно раздела заявки «Publication». В верхней части окна в поле с желтой полосой будет содержаться информация, которая препятствует испрашиванию отсроченной публикации заявки, если среди указанных Договаривающихся сторон есть страны, законодательство которых не допускает отсрочку публикации.

\section{- PUBLICATION}

\section{PUBLICATION OF INTERNATIONAL REGISTRATION Help}

The following Contracting Parties have been designated under the 1999 Act: UA. The law of these Contracting Parties does not provide for the deferment of the publication.

Date of publication

Date of publication *

Publication six months after date of international registration

Immediate publication

O Deferment of publication for [in months starting from the earliest priority date if priority is claimed]:

Рисунок 17 - окно раздела заявки «Publication»

В случае если отсрочка публикации необходима такие Договаривающиеся страны следует исключить из указания, в противном случае отсрочка публикации не будет предоставлена. В приведенном на рисунке 17 примере Договаривающейся стороной, на территории которой испрашивается охрана промышленных образцов указана Украина, законодательство которой не допускает отсрочку публикации, о чем в поле с желтой полосой содержится предупреждение. В связи с этим для указания даты публикации в данном примере активированы только две дефиниции: Publication six months after date of international registration (публикация через 6 месяцев с даты международной регистрации) и Immediate publication (немедленная публикация). Дефиниция отсрочка публикации (Deferment of publication...) в этом случае не активирована. Для подтверждения выбранной даты нужно нажать кнопку «Save». 
Еще одним обязательным разделом является «Signature» - (Подпись), вид окна действий которого показан на рисунке 18.

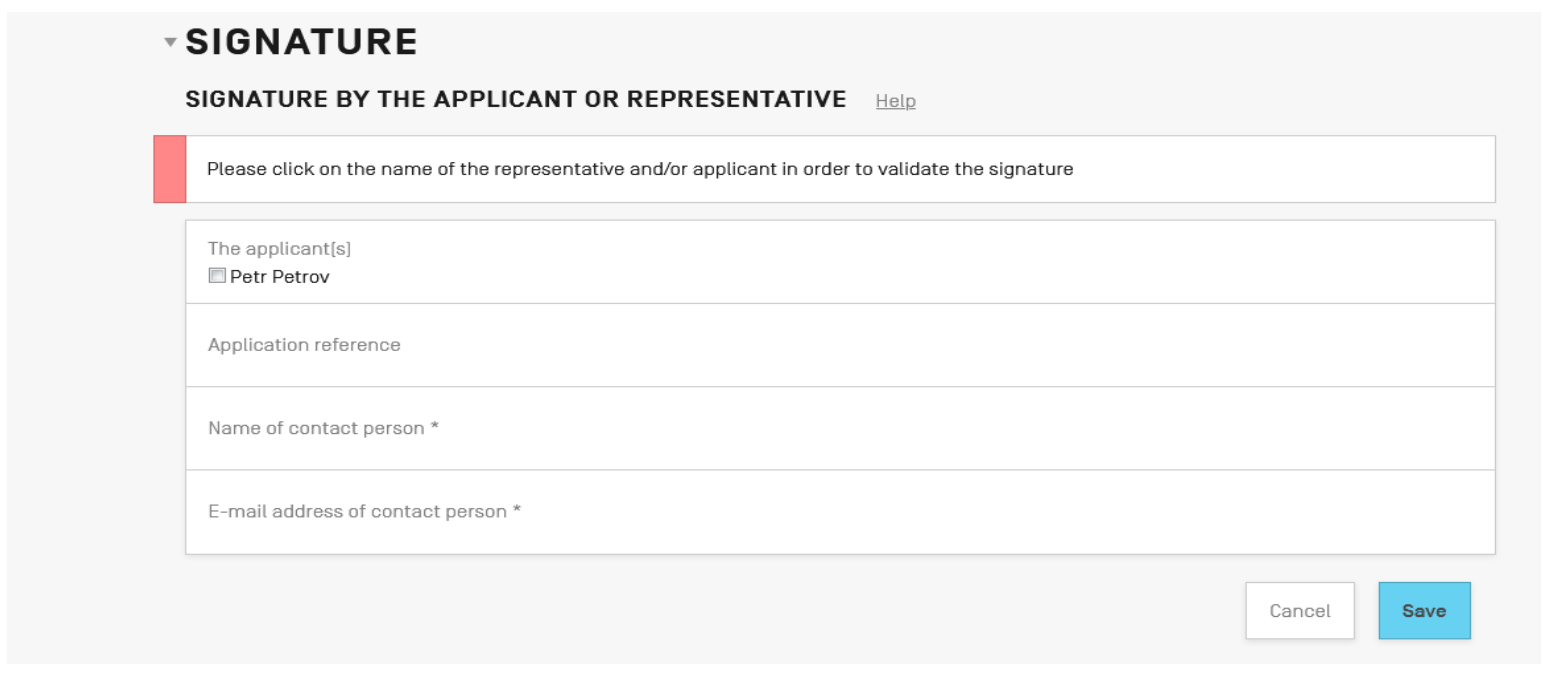

Рисунок 18 - Окно раздела заявки «Signature»

В белом поле с красной полосой содержится указание следующего содержания - «Пожалуйста, нажмите на имя представителя и/или заявителя, чтобы подтвердить подпись».

Подписать заявку может заявитель, указанный в разделе «Applicant», или представитель, если он был указан, и к заявке была прикреплена доверенность. Чтобы идентифицировать человека, подписавшего заявку нужно сделать отметку в соответствующем боксе.

Если не был указан адрес электронной почты необходимо заполнить поля «Name of contact person» - (Имя контактного лица) и «E-mail address contact person» (Адрес электронной почты контактного лица) прежде, чем сохранить раздел «Signature». Если указанная информация не будет введена, система обозначит это как ошибку, выделив красным цветом названия незаполненных полей.

После нажатия кнопки «Save» - (Сохранить) активируются кнопки «Summary» - (Сводка) и «Payment Validate»- (Оплата/Подтверждение) (см. рис.19).

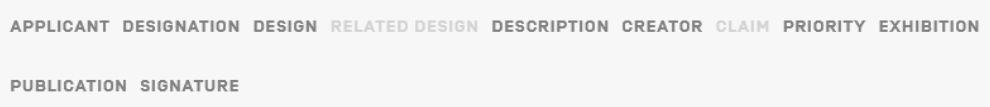

\section{WIPO REFERENCE 105511}

Рисунок 19 - Окно подачи заявки с активированной кнопкой «Payment Validate» 
Если в заявке не будут заполнены все необходимые разделы кнопка «Payment Validate» не будет активирована.

При нажатии кнопки «Раyment Validate» открывается сводное окно уплаты пошлин и отправки заявки в ВОИС (см. рис. 20), в котором показана рассчитанная встроенным в систему калькулятором пошлин общая сумма, требуемая к оплате, суммы сборов, уплачиваемых в пользу МБ ВОИС и суммы за указание выбранных Договаривающихся сторон.

Все пошлины должны быть уплачены при подаче заявки. Исключение составляет пошлина за публикацию в случае отсрочки публикации. В случае если заявитель желает оплатить сборы позднее, то необходимо сделать отметку в боксе с напоминанием о том, что пошлина должна быть уплачена не позднее, чем за 3 недели до истечения срока отсрочки публикации.

Прежде чем отправить заявку необходимо внимательно ее проверить, просмотрев краткое содержание и изображения промышленных образцов. Для этого в окне имеются две кнопки действий: «Summary» - (Сводка) и «Preview reproduction» - (Предварительный просмотр изображений). Для подтверждения готовности заявки к отправке необходимо поставить отметку в боксе рядом с надписью красным шрифтом, гласящей: «Я подтверждаю, что ознакомился с заявкой и ее содержанием, включая репродукции и сопроводительные документы». Ниже в поле серого цвета содержится предупреждение о том, что после отправки изменения в заявку внести будет невозможно. После нажатия кнопки «Save» - (отправить), появится окно, позволяющее выбрать способ оплаты пошлин из выпадающего меню.

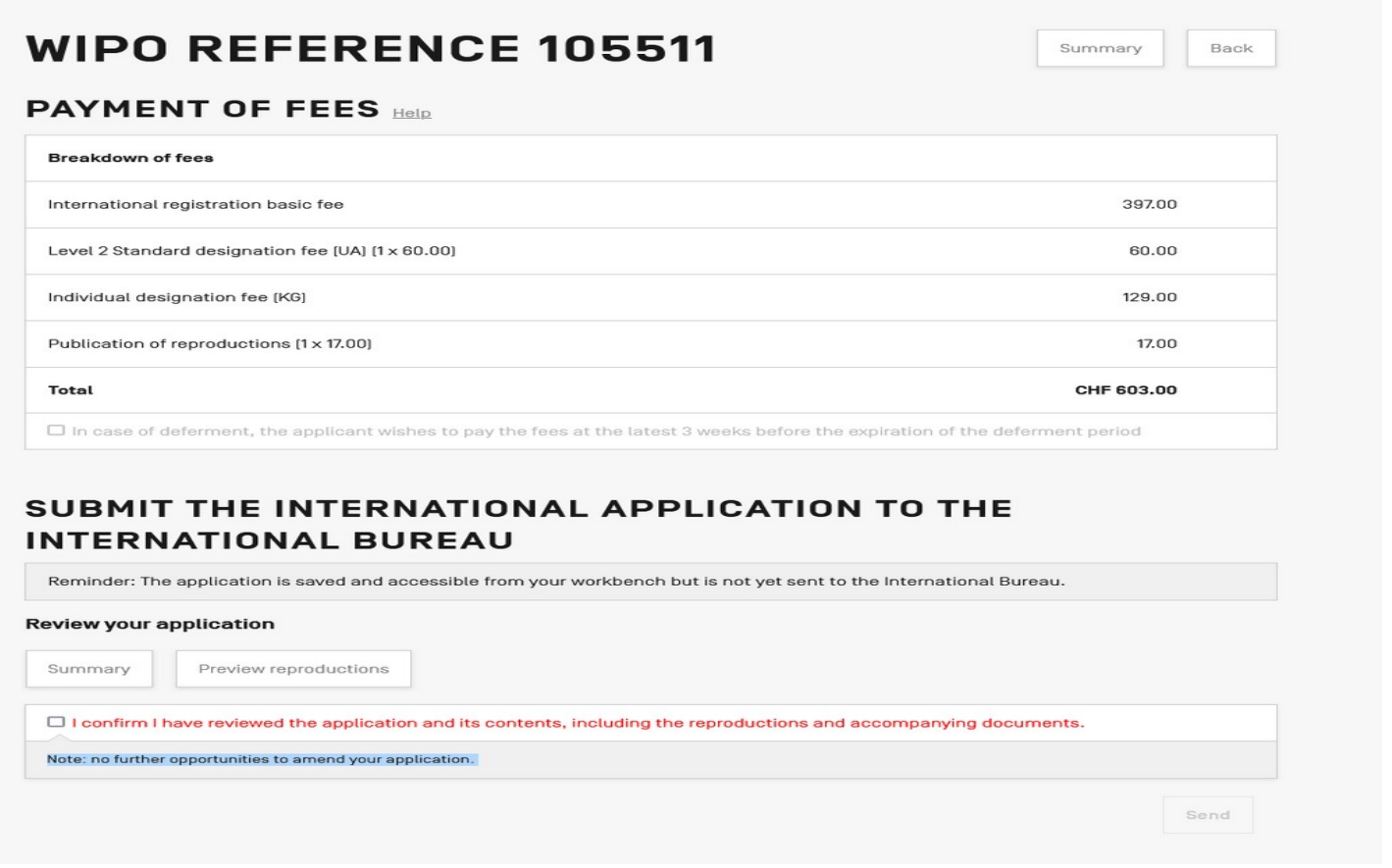

Рисунок 20 - Сводное окно оплаты пошлин и отправки заявки 
Если в разделе «Designation» указываются страны, законодательство которых требует предоставления дополнительных данных, то функциональные возможности сервиса E-Filing позволяют обеспечить выполнение этих требований при подаче заявки. В зависимости от выбора в разделе «Designation» Договаривающихся сторон будут активированы разделы заявки, необходимые для внесения данных, и выведены на экран необходимые подсказки.

Так в разделе «Creator» сведения об авторе можно приводить при указании любых Договаривающихся сторон. Однако система подскажет, что при указании Румынии, Финляндии, Ганы, Венгрии, Исландии, Мексики и США приведение сведений о личности автора носит обязательный характер.

При указании в разделе «Designation» США или Вьетнама становится обязательным для заполнения раздел «Claim», касающийся притязаний, и раздел «Description» - (описание), при указании США.

Заполнять раздел «Description» - Описание требуется не только при указании США, поэтому система выдаст подсказку для каких Договаривающихся сторон заполнение этого раздела обязательно, а для каких желательно представить описание.

Ряд разделов заявки может заполняться по желанию заявителя. В число таких разделов входит раздел «Рriority» - Приоритет, который заполняется только в том случае, когда по заявке испрашивается приоритет по другой более ранней заявке на основании статьи 4 Парижской конвенции.

Также заявитель может заполнить раздел «Related Design» - (связанные образцы) в случае указания в разделе «Designation» таких Договаривающихся сторон как Япония и Республика Корея, если захочет воспользоваться нормой о связанных образцах, поскольку только в национальном законодательстве этих стран содержится норма о связанных (родственных) образцах [8].

Если при подаче заявки заявитель пожелает воспользоваться льготами, предоставляемыми некоторыми Договаривающимися сторонами, заполняется раздел «Optional Content», который содержит следующие опции:

- «Declaration concerning exception to lack of novelty» - (льгота по новизне).

«Льготой по новизне» заявитель может воспользоваться в том случае, когда имело место раскрытие им информации о заявленном промышленном образце до даты подачи международной заявки. Норма о «льготе по новизне» имеется в законодательстве многих стран. Однако в соответствии с законодательством Японии и Республики Корея, для получения данной льготы заявителю необходимо при подаче заявки или в течение 30 дней с даты подачи заявки подать в ведомства указанных стран заявление о предоставлении льготы по новизне и представить документ, подтверждающий, что раскрытие произошло в срок, не превышающий 6 месяцев до даты международной регистрации. Подать заявление о предоставлении 
льготы в ведомства Японии и Республики Корея в столь короткий срок бывает проблематично. В связи с этим в данном разделе при указании Японии и/или Республика Корея появляется опция «Declaration concerning exception to lack of novelty», используя которую можно подать заявление о предоставлении льготы по новизне при подаче заявки.

- Опция «Eligibility for protection» - предназначена для заполнения при указании США.

Опция позволяет приложить к международной заявке заявление о раскрытии для направления в ведомство США.

- Опция «Economic status for US», позволяющая заявителю ввести сведения, необходимые для получения льготы по оплате индивидуальной пошлины за указание США, предусмотренной законодательством США.

Для удостоверения статуса микро-предприятия заявитель должен представить форму сертификации микро-предприятия PTO/SB/15A или PTO/SB/15B в соответствии с параграфом 123 раздела 35 Кодекса США.

- Опция «Economic status for MX», позволяющая заявителю ввести сведения для предоставления скидки 50\% на пошлину за указание Мексики. Скидку могут получить заявители, имеющие следующий статус: физическое лицо, малое или микро-предприятие, государственное или частное высшее учебное заведение, государственный научно-исследовательский институт.

- Опция «Economic status for IL, позволяющая претендовать на снижение индивидуальной пошлины за указание Израиля.

Детальное описание действий, связанных с заполнением факультативных и опционных разделов электронной заявки, приведено в приложениях к отчету, которые в связи с их значительным объемом не включены в данный препринт.

\section{5. Вкладка «Filed application(s) » - (Поданные заявки)}

Вкладка "Filed application(s)" - «Поданные заявки» позволяет при ее открытии просмотреть все ранее поданные с помощью интерфейса еНague заявки. На рисунке 21 показан вид окна при открытии вкладки "Filed application(s)"

В открывшемся окне появляется следующая информация по отправленным заявкам:

- WIPO reference - номер заявки, присвоенный ВОИС;

- Filing date - дата подачи;

- Applicant(s) - заявитель;

- Product Indication - обозначение изделия, к которому относится дизайн;

- Designation(s) - указанные Договаривающиеся стороны;

- Acknowledgement of receipt - Подтверждение получения заявки. 


\section{EHAGUE}

\begin{tabular}{|c|c|c|c|c|c|c|c|c|}
\hline New & \multicolumn{2}{|c|}{ Filed application[s] } & Draft[s] [11] & \multicolumn{2}{|c|}{ eHague communication } & eHague tutorial & & \\
\hline \multicolumn{2}{|c|}{ WIP0 reference } & \multicolumn{2}{|c|}{ Filing date $\hat{v}$} & Applicant[s] $\hat{v}$ & \multicolumn{2}{|c|}{ Product Indicatio... } & Designation[s] $\hat{v}$ & Acknowledgemen... \\
\hline
\end{tabular}

Рисунок 21 - Окно действий вкладки «Filed application(s)»

Вкладка позволяет получать подтверждения получения МБ ВОИС отправленных с использованием сервиса еHague международных заявок. Число в скобках, показываемое на вкладке Filed application(s) соответствуют числу посланных заявок.

\section{6. Вкладка «Draft application(s)» - (Черновики заявок)}

Вкладка «Draft application(s)» -(черновики заявок), предназначена для сохранения незаконченных заявок (черновиков), которые можно в любое время редактировать. На рисунке 22 представлено окно вкладки «"Draft application(s)».

\begin{tabular}{|c|c|c|c|c|c|c|c|}
\hline New & & & Draft[s] [3] & eHague communication & eHague tutorial & & \\
\hline \multicolumn{2}{|c|}{ WIPO reference - } & \multicolumn{2}{|c|}{ Creation date $\hat{v}$} & Applicant[s] $\hat{v}$ & Locarno Class ̂े & \multicolumn{2}{|l|}{ Designation[s] $\hat{v}$} \\
\hline \multicolumn{2}{|c|}{ WIP0105364 } & \multicolumn{2}{|c|}{$31 / 05 / 2021$} & Petrov Petr & 12 & MX, us & $\theta$ \\
\hline \multicolumn{2}{|c|}{ WIP0104250 } & \multicolumn{2}{|c|}{$26 / 04 / 2021$} & Petrov Petr & & $E M, J P, K R, M X, ~ U S$ & $\theta$ \\
\hline \multicolumn{2}{|c|}{ WIP0103556 } & & $4 / 2021$ & Stepanov Stepan & 12 & $\mathrm{KR}$ & $\theta$ \\
\hline
\end{tabular}

Рисунок 22 - Окно вкладки «Draft application(s)».

Все незаконченные заявки сохраняются в данной вкладке. Для возобновления редактирования заявки следует нажать на функциональную кнопку «Open edit» (Открыть правку), изображенную в виде карандаша, и система перенаправит 
пользователя в интерфейс подачи заявки в раздел Applicant - (Заявитель) (см. рис. 10).

Кнопка действий «Удалить» - корзина, позволяет удалять черновики заявок из списка без возможности их восстановления.

Число в скобках, показываемое на вкладке «Draft application(s)» соответствуют числу незаконченных заявок.

\section{7. Вкладка «еHague Communication» - (Коммуникации)}

Вкладка «Communication» - («коммуникации) предназначена для получения уведомлений от МБ ВОИС в отношении международных заявок, поданных через интерфейс еHague, и ответа на них в режиме онлайн.

На рисунке 23 показано окно вкладки «Communication».

МБ ВОИС может направлять сообщения о нарушениях, выявленных в ходе формальной экспертизы заявки, на которые требуется предоставление ответа, а также направлять уведомления, не требующие ответа. Заявитель информируется о поступлении нового сообщения по электронной почте.

\section{COMMUNICATION}

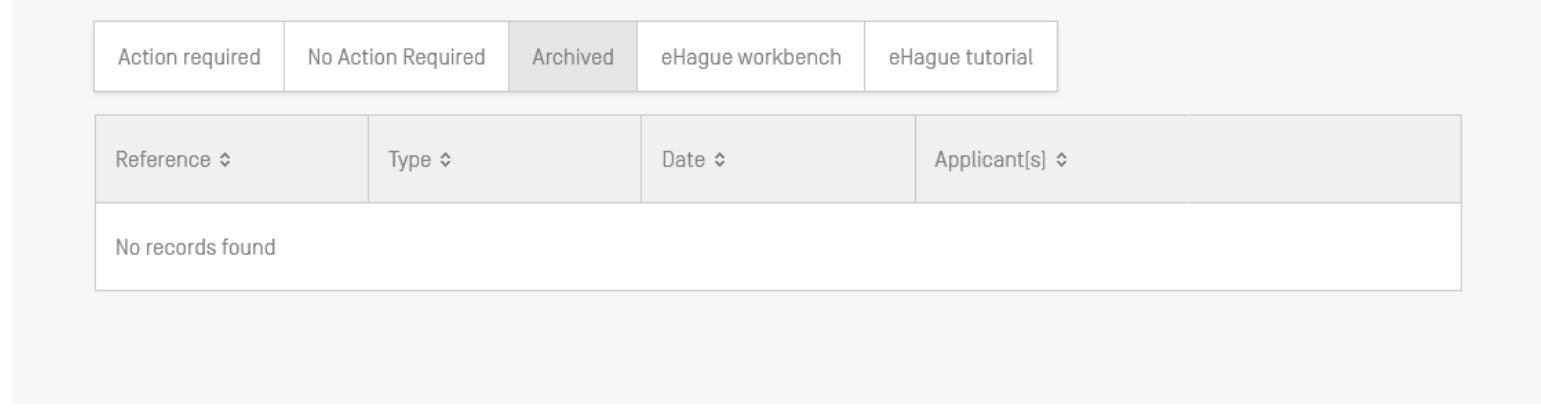

Рисунок 23 - Окно вкладки «Communication»

Поступающие сообщения распределяются по соответствующим вкладкам интерфейса «еHague Communication».

Во вкладке «Action required» - размещаются уведомления, требующие ответа. Чтобы найти сообщение для исправления нарушений, необходимо убедиться, что вкладка "Необходимые действия" выделена светло-серым цветом. Если данная вкладка не выделена, необходимо нажать на нее. Во вкладке "Необходимые действия" можно найти список сообщений для исправления нарушений или незначительных дефектов, в отношении которых ожидается исправление. Пользователь имеет возможность загрузить уведомление, нажав на значок «PDF» в столбце «Письмо» («Letter»). 
В данной вкладке имеются контекстные кнопки, позволяющие выполнять различные действия при наведении курсора «мыши» на нужную строку:

- кнопка «Ответить» («Reply») открывает форму для ответа онлайн на сообщение об исправлении определенных нарушений или незначительных дефектов;

- кнопка «История» («History») позволяет просмотреть историю сообщений, относящихся к каждой международной заявке;

- кнопка «Оплатить онлайн» («Раy online») позволяет осуществить оплату требуемых пошлин, где это требуется;

- кнопка «Подтверждение получения» («Acknowledgement of receipt») позволяет загрузить подтверждение получения для отмеченной заявки.

Необходимо обращать внимание на то, что для ответа используется официальная форма, которая сохраняется в деле заявки. Следует тщательно подготовить и внимательно просмотреть ответ перед отправкой. Используя форму для ответа, можно осуществлять следующие действия:

- ввести ответ в текстовое поле;

- приложить документы в формате PDF (доверенность, декларация автора, форма сертификации микропредприятия и другие документы);

- прикрепить изображения, указав номер промышленного образца и изображения, после чего загрузив изображения в формате JPG или TIF; следует обратить внимание, что номер изображения состоит из двух цифр, разделенных точкой, первая цифра означает номер промышленного образца, вторая - номер изображения.

После того, как необходимые действия завершены, следует нажать на кнопку «Представить свой ответ» - «Submit your reply».

Вкладка «No Action Required» - (Никакие действия не требуются) содержит письма, на которые не требуется ответа, и уведомления об отказе по международным заявкам. Количество непрочитанных сообщений показано в круглых скобках. Данные сообщения не требуют каких-либо действий. После прочтения сообщения доступны в данной вкладке 30 дней, после чего они автоматически перемещаются во вкладку «Архивировано».

Вкладка «Archived» - (Архивировано) позволяет просматривать сообщения, касающиеся зарегистрированных и отклоненных заявок. Также в этой вкладке размещаются уведомления, не требующие ответа, которые перемещаются в раздел через 30 дней после их прочтения.

Интерфейс «еHague Communication» также содержит вкладку «еHague workbenh»- (Рабочий стол), позволяющую вернуться в исходную точку главного диалогового окна, и/или перейти во вкладку «еHague tutorial», дающую доступ к Руководству «Filing Tutorial», к которому также можно перейти из главного диалогового окна через вкладку«еHague tutorial» (см. рис. 7) . 


\section{4. Пользовательский сервис для продления действия международных регистраций E-Renewal}

C помощью интерфейса электронного продления E-Renewal, перейти к которому можно, выбрав функцию RENEW на странице сервиса eHague (см. рис. 5), можно продлить действие международной регистрации полностью или частично.

После нажатия кнопки «Get started» пользователь будет перенаправлен на страницу электронного сервиса E-Renewal (см. рис. 24).

Пользовательский сервис для продления международных регистраций ЕRenewal достаточно прост и удобен в использовании. Для продления международной регистрации достаточно указать номер международной регистрации в соответствующем поле (см. рис.24), после чего нажать кнопку «SUBMIT».
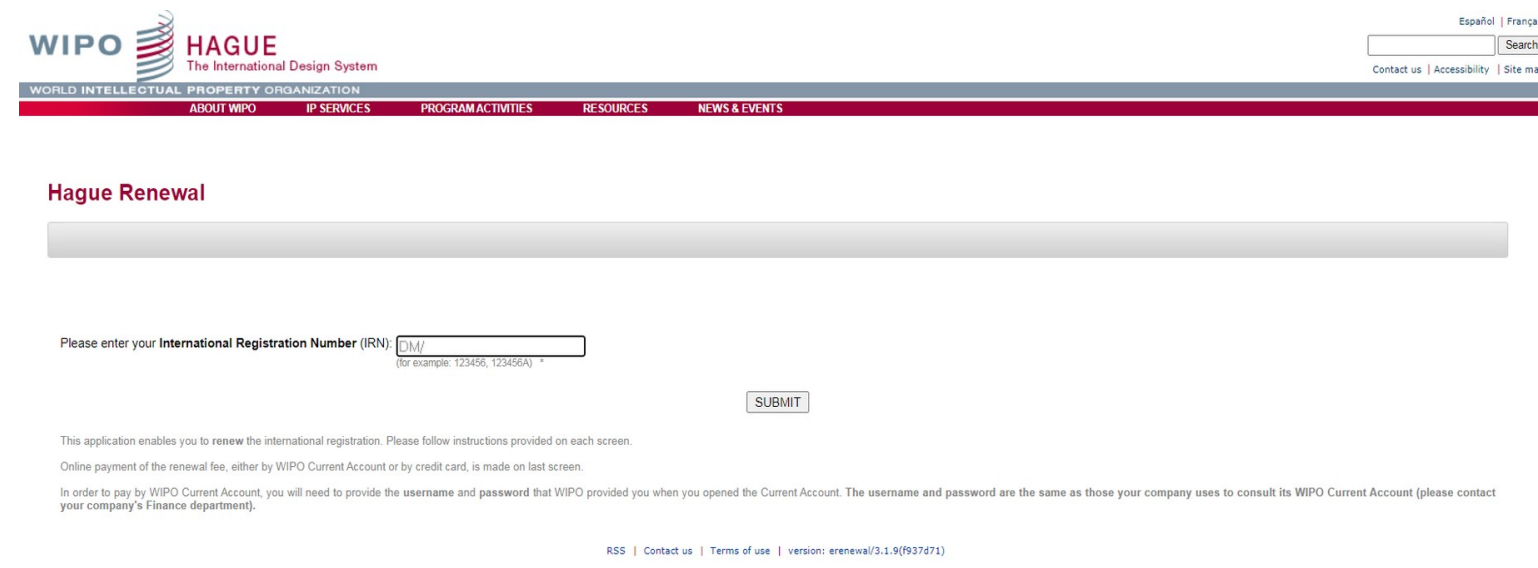

Рисунок 24 - Окно сервиса E-Renewal

Чтобы продлить действие международной регистрации пользователям необходимо следовать инструкциям системы, приведенным на каждом экране.

В случае частичного продления (то есть только в отношении некоторых промышленных образцов и/или некоторых указанных Договаривающихся Сторон), интерфейс E-Renewal позволяет владельцам международных регистраций указывать объем продления более детально. В частности, интерфейс E-Renewal позволяет выбирать различные группы указанных Договаривающихся Сторон, для которых различные группы промышленных образцов подлежат продлению.

Интерфейс E-Renewal автоматически подсчитывает размер пошлин, которые должны быть уплачены за продление международных регистраций, на основе сведений, введенных владельцем конкретной международной регистрации. При этом владелец может просматривать изображения промышленных образцов, содержащиеся в международной регистрации. Интерфейс E-Renewal позволяет производить оплату пошлин за продление онлайн через платежную систему, 
предлагающую различные методы платежа, в соответствии с профилем учетной записи пользователя.

Альтернативным способом доступа к сервису E-Renewal является доступ через сервисы оплаты пошлин.

\section{5. Сервисы ВОИС онлайн - оплаты пошлин}

Для оплаты различных видов пошлин в электронном виде ВОИС предоставляет доступ к сервисам онлайн - оплаты. Оплата регистрационных пошлин за заявку при электронной подаче международной заявки на промышленный образец с использованием сервиса «еHague» онлайн осуществляется через данный сервис. C помощью сервиса «Е-Рау» можно оплатить в режиме онлайн пошлины за продление, сборы, указанные в письмах о нарушениях, или осуществить последующую оплату регистрационных пошлин, которые не были оплачены при подаче заявки. Для онлайн - оплаты продления срока действия международных регистраций можно использовать сервис «E-Renewal».

Для того чтобы иметь возможность пользоваться данными сервисами ВОИС необходимо быть зарегистрированным пользователем сайта ВОИС, то есть необходимо иметь учетную запись ВОИС «WIPO Account».

Все платежи будут обрабатываться в швейцарских франках (CHF).

\section{1. Оплата регистрационных пошлин с использованием сервиса «eHague»}

В соответствии с Правилом 12(2) Инструкции [4] пошлины в отношении заявки на международную регистрацию промышленных образцов уплачиваются при ее подаче. Исключение составляет пошлина за публикацию при отсрочке публикации, которая может быть оплачена позднее. Поэтому, для того чтобы произвести оплату, следует нажать кнопку «Payment/Valid» (Оплата/действительна), расположенную под навигационной панелью справа от кнопки «Summary» - (Сводка) (см. рис. 19).

Как только будет нажата кнопка «Рayment/Valid» пользователь перенаправляется на экран сервиса Е-Рау, позволяющий выбрать способ оплаты пошлин (см. рис. 25). 


\section{PAYMENT DETAILS}

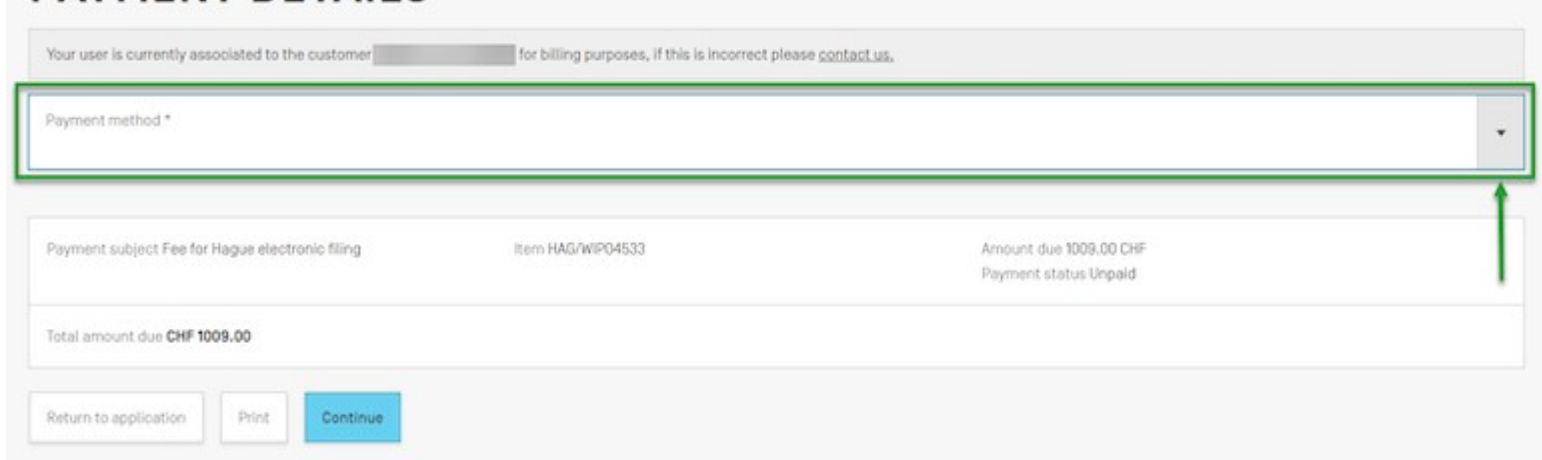

Рисунок 25 - Окно для выбора способа оплаты пошлин в выпадающем меню поля «Payment method»

В выдающем меню поля «Рayment method», отображающем доступные способы оплаты, необходимо выбрать способ, которым будет оплачена пошлина:

- с текущего счета ВОИС (Current Account at WIPO);

- кредитной картой (credit card);

- банковским переводом (bank transfer);

- с использованием международной дебетовой электронной платежной системы PayPal.

При любом способе оплаты пошлины уплачиваются в швейцарских франках.

\section{2. Оплата с текущего счета ВОИС (Current Account at WIPO)}

Текущий счет ВОИС предназначен для клиентов, которые регулярно осуществляют (или планируют осуществлять) финансовые операции с Организацией. Счет является бесплатным, однако необходимо поддерживать баланс, превышающий 200 швейцарских франков. Если баланс упадет ниже этой суммы, то будет направлено уведомление по электронной почте о необходимости пополнения. Просмотреть баланс счета можно в любое время. ВОИС оставляет за собой право закрыть любой Текущий счет в ВОИС, который был бездействующим (т. е. никаких операций по счету и со счета) в течение более двух лет, или если остаток средств упадет ниже 200 швейцарских франков. Если ответа на сообщения, касающиеся Текущего счета, не поступит в ВОИС, это может привести к списанию любого оставшегося остатка.

Если у заявителя открыт Текущий счет ВОИС, он будет автоматически выбран на экране для оплаты пошлин, как показано на рисунке 26. 


\section{PAYMENT DETAILS}

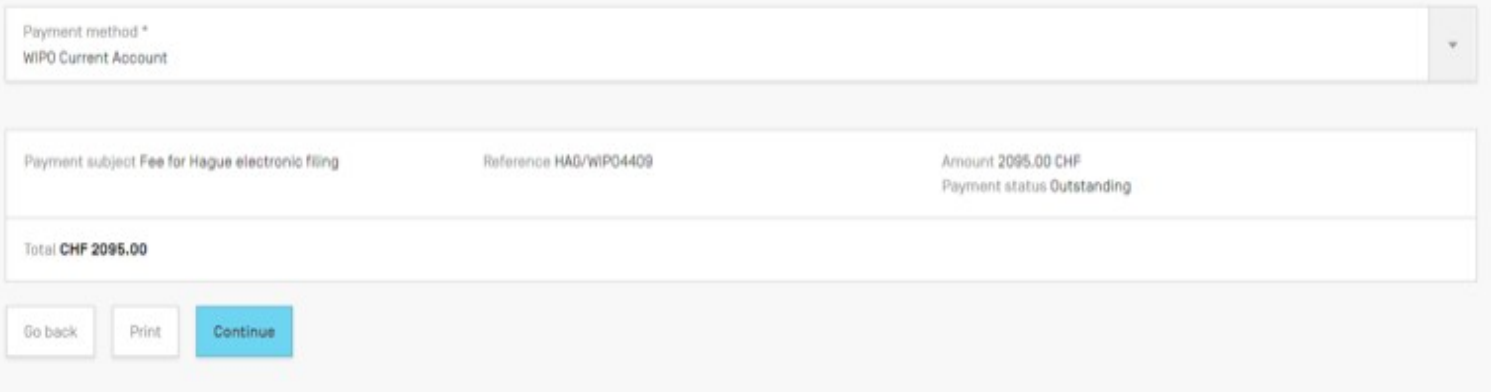

Рисунок 26 - Оплата с Текущего счета

Перед нажатием синей кнопки «Continue» - (продолжить) следует проверить правильность общей суммы. После обработки платежа на экране появится подробная информация о платеже (см. рис. 27)

SUMMARY ACTIVITY PENDING [1]

\section{PAYMENT DETAILS}

\section{BASKET [EPMT-IV8V-OFFK]}

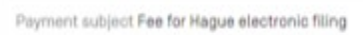

\section{PAYMENT ITEMS}

\begin{tabular}{|c|c|c|}
\hline Reterencese & Amount & Payment status \\
\hline 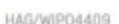 & 2005 рес cus & Derouked \\
\hline
\end{tabular}

Рисунок 27 - Экрана с подробной информацией о платеже

Если в правом столбце в реквизите «Payment status»- (Статус платежа) указано «Received» - (Получено), это означает, что платеж успешно прошел. Можно проверить статус платежа по текущему счет, нажав ссылку «асtivity». На рисунке 28 показано окно платежей по текущему счету. 


\section{ACTIVITY}
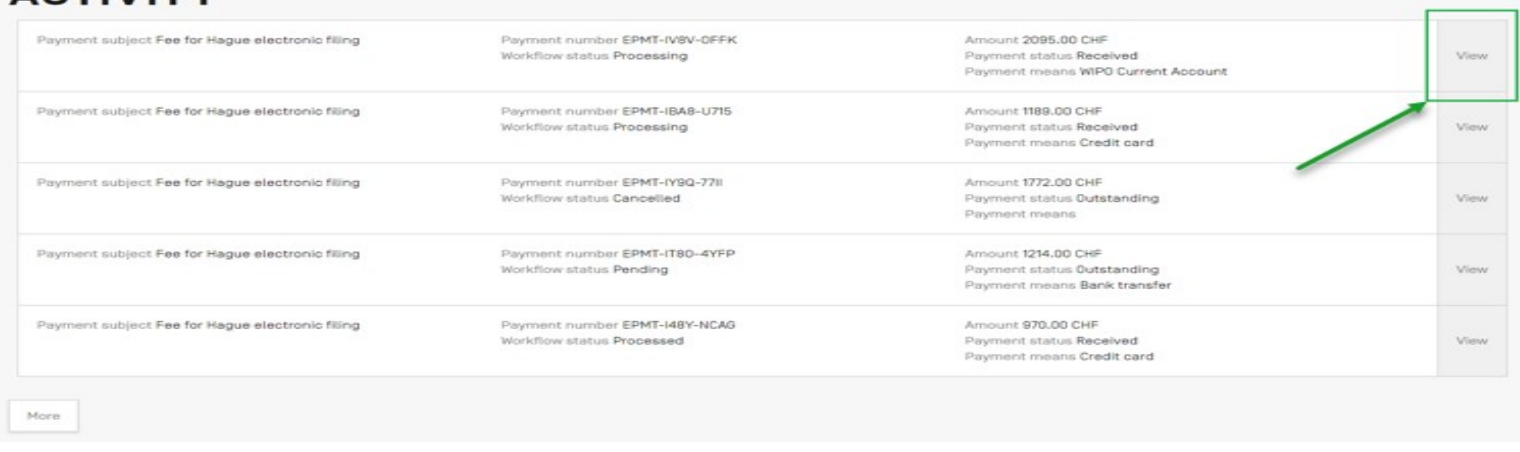

Рисунок 28 - Окно платежей по текущему счету

В списке на экране будет представлена информация обо всех непогашенных или полученных от заявителя платежах. Подробную информацию о транзакции можно увидеть, нажав кнопку «View» - (Просмотр) в конце каждой строки списка.

\section{3. Оплата кредитной картой}

При отсутствии Текущего счета ВОИС пошлины можно оплатить кредитной картой. Для этого в окне для выбора способа оплаты пошлин выбирается опция «credit card».

В появившемся после выбора опции окне (см. рис. 29) следует проверить правильность указанной общей суммы счета, нажать кнопку «Continue» (продолжить).

\section{PAYMENT DETAILS}

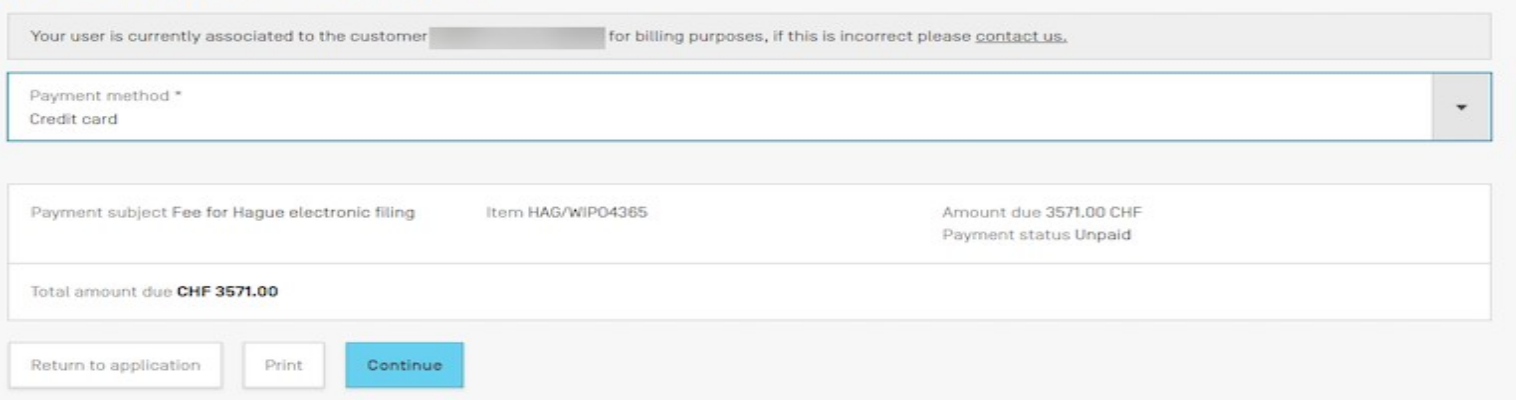

Рисунок 29 - Экран оплаты кредитной картой

После этого появляется экран с уведомлением о шифровании браузера и условиях оплаты, в котором нужно ввести данные своей кредитной карты. 
После ввода данных кредитной карты следует нажать кнопку «Рау» (Оплатить). После обработки платежа появится экран успеха оплаты (см. рис. 30).

Payment Success Payment Success

\section{BASKET [EPMT-ID9E-7NOY]}

\section{PAYMENT ITEMS}

\begin{tabular}{|l|l|l|}
\hline Item & Amount due & Amount received \\
\hline HAG/WMP04365 & $3571.00 \mathrm{CHF}$ & Paid status \\
\hline
\end{tabular}

Рисунок 30 - Экран успеха оплаты кредитной картой

Увидеть подтверждение получения оплаты пошлин по поданной заявке можно во вкладке «Filed application(s)» - (Поданные заявки) сервиса еHague. Открыв данную вкладку, следует навести курсор мыши на строку, содержащую нужную заявку, и нажать кнопку «Acknowledgement of receipt» - (Подтверждение получения), чтобы загрузить подтверждение получения оплаты пошлин по этой заявке (см. рис. 31).

\section{E-HAGUE}

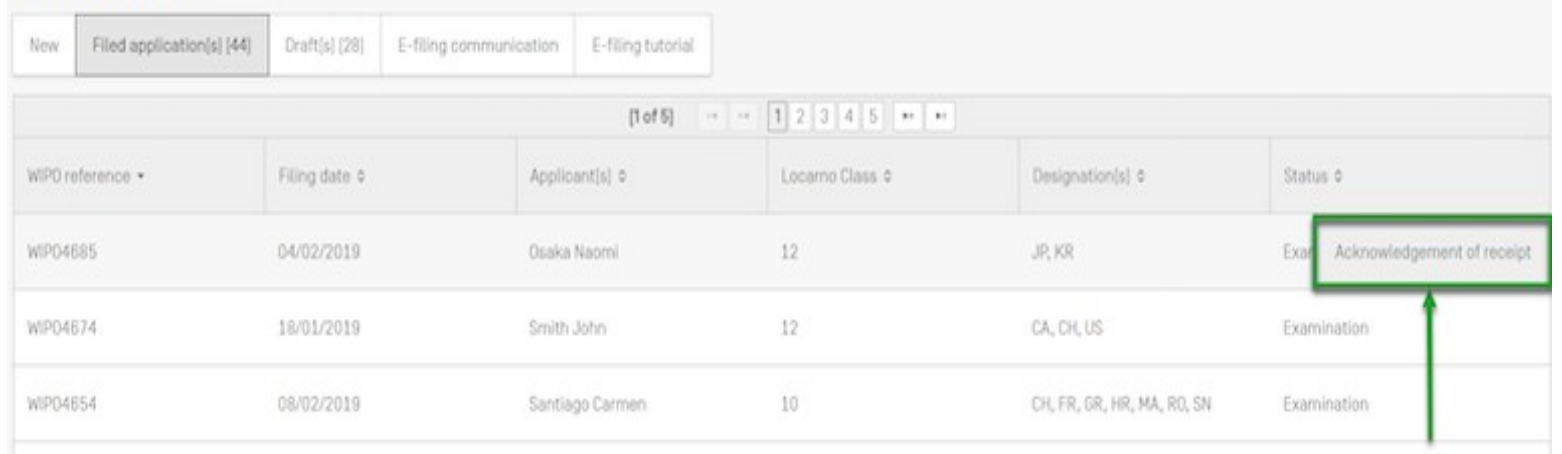

Рисунок 31 - Экран подтверждения получения оплаты пошлин 
Данная функция загрузки подтверждения получения оплаты доступна при оплате любым способом из числа, предлагаемых системой, кроме способа «bank transfer».

\section{4. Оплата банковским переводом}

Чтобы оплатить пошлины банковским переводом выбирается опция «bank transfer» в раскрывающемся списке способов оплаты.

Экран оплаты банковским переводом показан на рисунке 32. После проверки в открывшемся окне (см. рис. 32) правильности общей суммы счета к оплате надо нажать кнопку «Continue» - (продолжить).

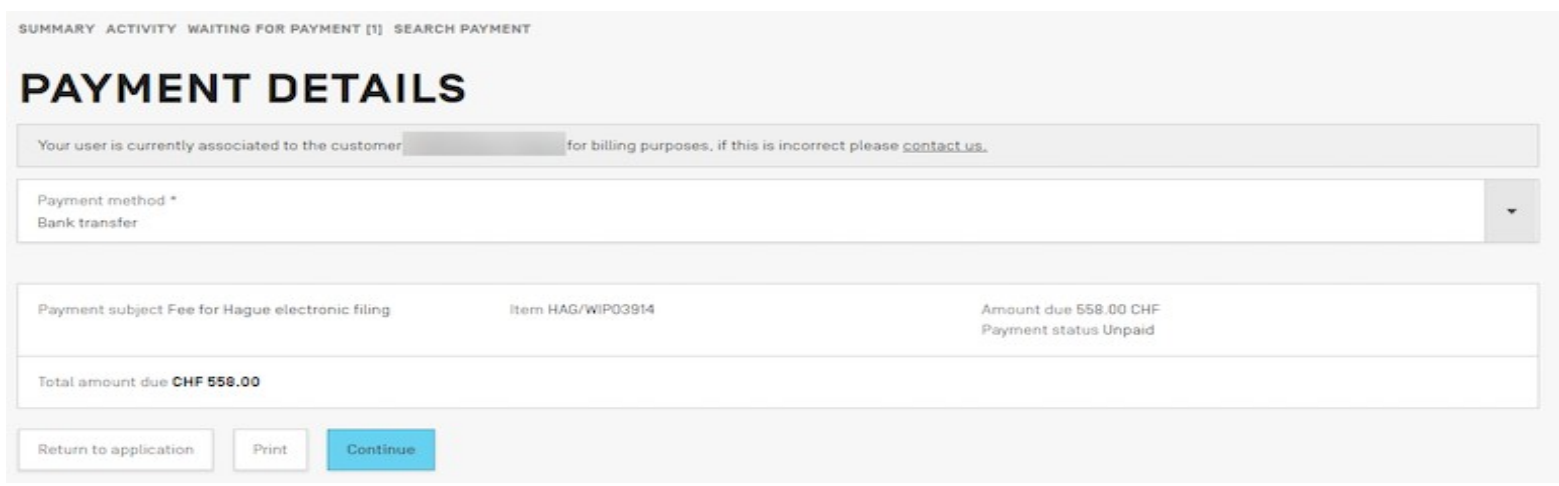

Рисунок 32 - Экран оплаты банковским переводом

После нажатия кнопки «Continue» - (продолжить) появляется экран с банковскими реквизитами счета ВОИС, на который зачисляются пошлины. Экран с банковскими реквизитами счета ВОИС (см. рис. 33).

В верхнем сером поле экрана содержится информация о том, что квитанция о перечисленной сумме пошлин высылается заявителю в течение 10 дней с даты отправки банковского перевода. Если по истечении 10 дней квитанция не будет выслана, заявителю предлагается связаться с МБ ВОИС. В сером верхнем поле экрана также содержится напоминание о том, что при оправке перевода необходимо убедится, что в платеже указаны реквизиты банковского счета ВОИС, иначе платеж за заявку не пройдет. 


\section{PAYMENT DETAILS}

The International Bureau of WIPO will send a receipt within 10 days of the date your bank or postal transfer is received. If you do not recelve a WIPO receipt within 10 days of

submitting your payment, please contact us.

Please ensure that the Reference is included in your bank tranafer, failure to do so will lead to your application not being proceased.

Beneficlary WIPO/OMP

IBAN CH51 04835048708081000

Swift/BIC CRESCHZZ80A

Bank Credit Suisse, 1211 Geneva 70, Switzertand

Reference to include in your payment EPMT-1093-PKYW

Total amount due $\mathrm{CHF} 613.00$

Send me these payment details by emai

BASKET [EPMT-I093-PKYW]

Рисунок 33 - Экран с банковскими реквизитами счета ВОИС

\section{5. Оплата с использованием международной дебетовой электронной платежной системы PayPal}

Электронная платёжная система PayPal позволяет создавать свой личный кошелек и через него совершать любые платежные операции: конвертировать свои деньги в любую валюту, отправлять деньги любому другому пользователю системы. Полный функционал сервиса был доступен в России с 2013 года. Однако с августа 2020 года российские пользователи не имеют возможности отправлять средства на другие счета в пределах России. Но возможность отправлять и получать деньги через иностранные кошельки, оплачивать покупки и услуги в интернете, в том числе регистрационные пошлины за подачу заявки, и возвращать деньги на свой банковский счет с помощью PayPal еще осталась.

Для оплаты пошлины с использованием платежной системы выбирают опцию «PayPal» в раскрывающемся списке способов оплаты. В открывшемся окне, показанном на рисунке 34, следует проверить правильность суммы пошлины и затем нажать кнопку«Continue» - (продолжить) для перехода на экран оплаты PayPal. 


\section{PAYMENT DETAILS}

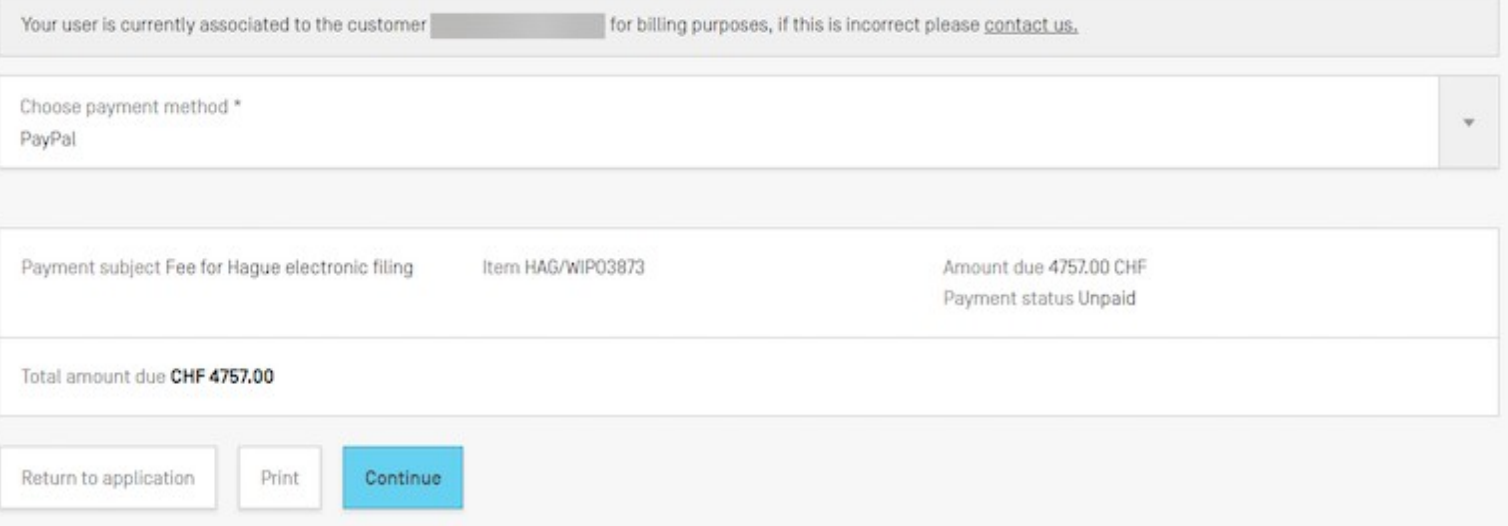

Рисунок 34 - Экран оплаты пошлин способом PayPal

Для того чтобы продолжить оплату PayPal нужно войти в систему с помощью учетных данных PayPal или путем ввода данных своей кредитной карты и созданием новой учетной записи PayPal.

После успешной оплаты через РаyPal производится возврат на рабочий стол сервиса «еHague». Чтобы увидеть подтверждение получения только что поданной заявки или предыдущей заявки, необходимо открыть вкладку «Filed application(s)» (Поданные заявки) сервиса «еНаguе», навести курсор мыши на строку, содержащую нужную заявку, и нажать на кнопку «Acknowledgement of receipt» - (Подтверждение получения) чтобы загрузить подтверждение получения для этой заявки (см. рис. 7).

\section{6. Сервис ВОИС онлайн - оплаты пошлин Е-Рау}

Сервис E-Рау, позволяет, оплачивать сборы, указанные в письмах о нарушениях или других сообщениях ВОИС, касающихся международных заявок, а также регистрационные пошлины, которые могут быть оплачены позднее (например, пошлина за публикацию при отсроченной публикации, вторая часть индивидуальной пошлины за указание США), и пошлины за продление действия международной регистрации. Оплата всех указанных видов пошлин и сборов через сервис Е-Рау возможна с Текущего счета ВОИС.

При отсутствии Текущего счета ВОИС указанные пошлины и сборы можно оплачивать через сервис Е-Рау кредитной картой, за исключением пошлин за продление действия международной регистрации. Для оплаты пошлин за продление в этом случае используется сервис E-Renewal. 
Для доступа к сервисам BOИС на WIPO IP PORTAL нужно иметь «Учетную запись ВОИС» («WIPO Account»). На странице IP PORTAL (см рис. 4) в «MENU» выбрать опцию «Рау».

После нажатия кнопки «Онлайн оплата» («Online Payment») открывается экран сервиса «Е-Рау» (см. рис.35).

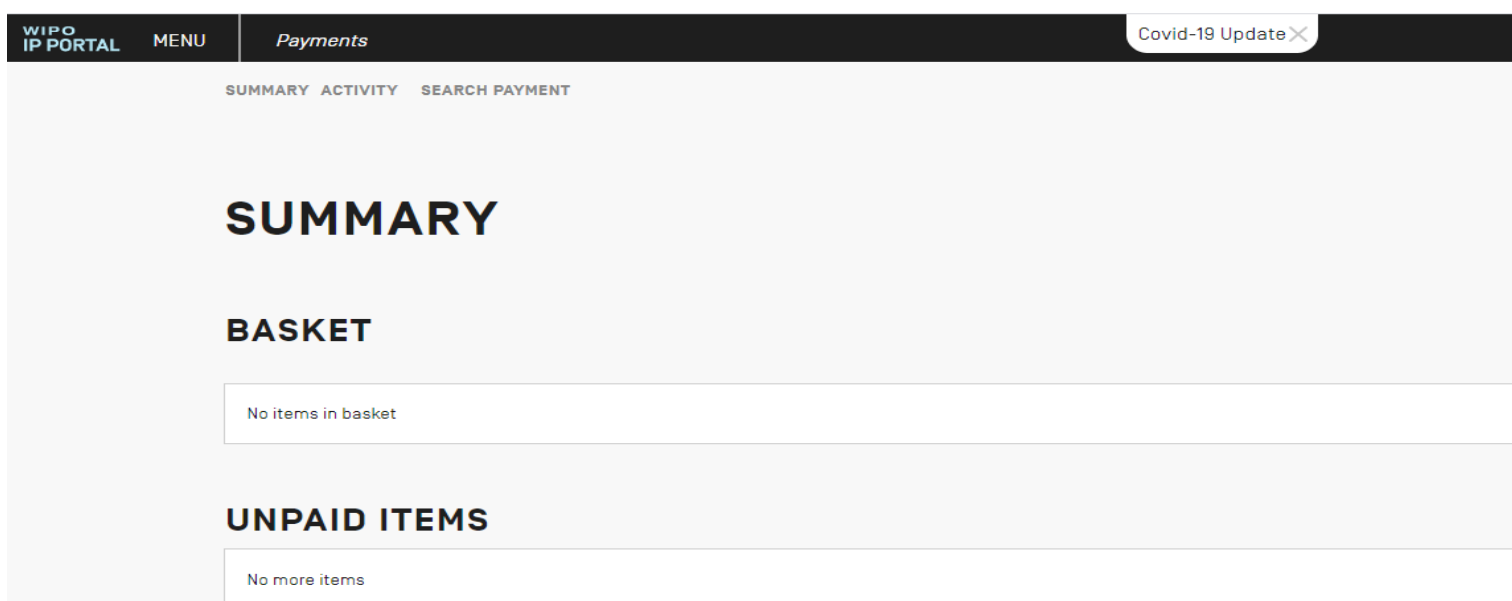

Рисунок 35 - Экран» сервиса «Е-Рау», раздел «SUMMARY».

В верхней части экрана расположены функциональные кнопки для доступа к следующим разделам сервиса: «SUMMARY» - (Обзор), «ACTIVITY» - (Действия), «SEARCH PAYMENT» - (Поиск платежа). По умолчанию открывается раздел «SUMMARY» -(Обзор)

На экране раздела «SUMMARY» представлены следующие поля: «BASKET» - (Корзина), где отображается информация в отношении оплаченных позиций, и «UNPAID ITEMS» - (Неоплаченные услуги), где представлены позиции, в отношении которых необходимо оплатить пошлины или сборы.

На рисунке 36 представлена страница, открывающаяся после нажатия функциональной кнопки «Действия» («ACTIVITY»). На данной странице сервиса «Е-Рау» можно осуществить поиск платежа по транзакциям «SEARCH TRANSACTIONS», для чего необходимо указать следующие данные: определенный период («Created [Date from]», «Created [Date to]»), сумму («Amount [from]», «Amount [to]»), позицию («Item») и статус платежа («Рayment status»). 


\section{ACTIVITY}

\section{SEARCH TRANSACTIONS}

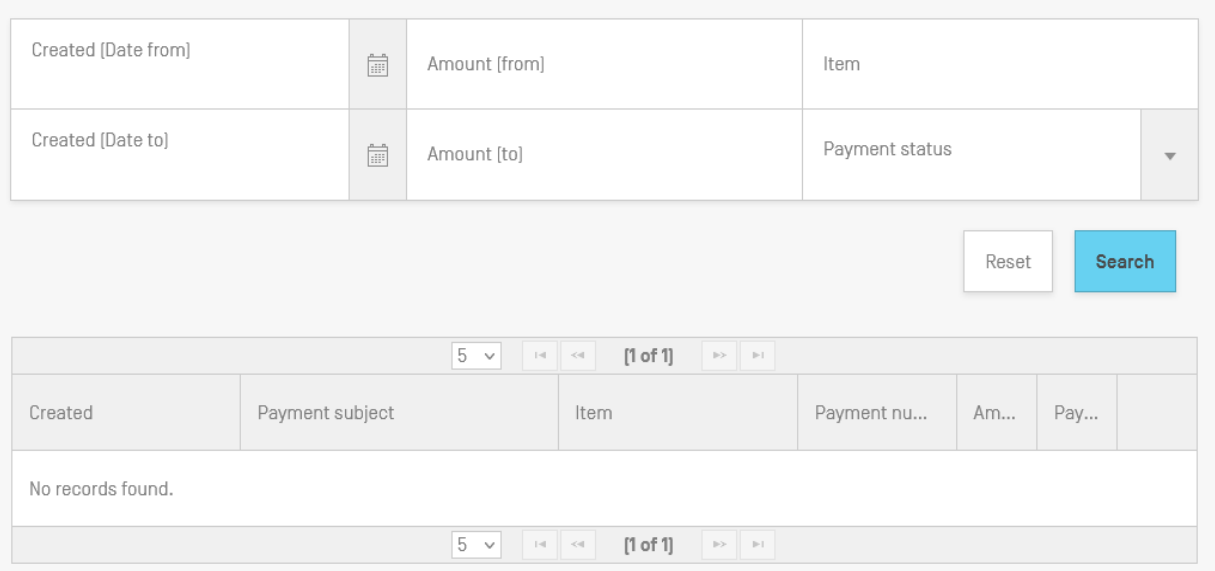

Рисунок 36 - Экран раздела «АCTIVITY» сервиса «Е-Рау»

Статус платежа предлагается выбрать из трех представленных: оплачено «Paid», не оплачено «Unpaid», истекший «Expired». Далее нажав на функциональную кнопку «Поиск» - «Search», система находит заданный платеж, который будет отображаться в нижней таблице страницы функциональной кнопки «Действия» «ACTIVITY». Найденная информация отображает следующие сведения: дату создания платежа «Created», назначение платежа «Payment subject», позицию «Item», номер платежа «Payment number», причитающуюся сумму «Amount due», статус платежа «Раyment status». При необходимости введенную информацию можно удалить, нажав на функциональную кнопку «Сбросить» - «Reset», и затем можно ввести в систему другие необходимые данные.

На странице «Поиск платежа» «SEARCH PAYMENT», которая представлена на рисунке 37, можно провести поиск по счету-фактуре - «SEARCH FOR INVOICE». В строке поиска необходимо ввести номер платежа «Enter payment number», после чего следует нажать на функциональную кнопку «Поиск» («Search»), при этом система предоставит найденную информацию.

При оплате пошлин через пользовательский сервис уплаты пошлин «Е-Рау» платежи по кредитным картам подтверждаются ВОИС только по электронной почте. Электронное сообщение будет сгенерировано и автоматически отправлено на адрес электронной почты, указанный вместе с платежной информацией. ВОИС не выдает 
никаких других платежных квитанций или счетов-фактур для онлайн-платежей по кредитным картам.

\section{SEARCH FOR INVOICE}

Рисунок 37 - Экран раздела «SEARCH FOR INVOICE» сервиса «E-Pay».

Доступ к странице пользовательского сервиса уплаты пошлин «Е-Рау» из раздела «MEHЮ» - «MENU» можно получить через опцию «Платежи» «PAYMENTS» (см. рис. 4). Далее выбирается опция «Оплатить» - «Рау», затем раздел «Оплата пошлин по Гаагской системе» - «Hague Fee Payment», после чего открывается экран раздела «SUMMARY» сервиса «E-Рау», показанный на рисунке 35.

Выйти на страницу пользовательского сервиса уплаты пошлин «Е-Рау» можно также из раздела «Resources» - (Ресурсы) страницы Гаагской системы (см. рис. 6). Для этого в меню подраздела «Fees \& payments» - (Пошлины и платежи) выбирается опция «Online payment» - (Онлайн - оплата).

При выборе данной опции открывается экран раздела «SUMMARY» сервиса «Е-Рау», показанный на рисунке 35.

\section{7. Онлайн - оплата продления срока действия международных регистраций}

Онлайн-оплата пощлин за продление производится, либо с текущего счета ВОИС, либо с помощью кредитной карты.

На экран сервиса онлайн - оплаты продления «E-Renewal» можно выйти через меню подраздела «Fees \& payments» - (Пошлины и платежи) раздела «Resources» - (Ресурсы), выбрав в нем опцию «Payment options» - (Способы оплаты) (см. рис. 6). После выбора данной опции открывается окно (см. рис. 38) с вариантами способов оплаты пошлин:

- оплата с помощью Текущего счета ВОИС («Option 1: Current Account at WIPO») 
- оплата с помощью кредитной карты («Option 2: credit card payments»);

- оплата с помощью банковского или почтового перевода

(«Option 3 and 4: bank or postal transfer»), которые не применяются для оплаты пошлин в электронном виде.

Payment methods

There are four ways to submit your fees to WIPO: Current Account at WIPO, credit card (in certain cases), bank transfer, or postal transfer (within Europe only). WIPO does not accept payment by cash or check. Any checks received will be returned to the sender.

To use some of our e-payment systems you must have a WIPO Account. Note: this is not the same

as a Current Account at WIPO.

- Option 1: Current Account at WIPO

- Option 2: credit card payments

- Options 3 and 4: bank or postal transfer

Warning - Failure to pay your fees in full will result in the issuance of an irregularity notice. The notice will contain a payment deadline (typically 3 months), after which the application will be deemed abandoned.

Рисунок 38 - Экран для выбора способа оплаты пошлин

При выборе опции «Option 2: credit card payments» появляется гиперссылка для перехода на сервис «E-Renewal» для онлайн - оплаты пошлин за продление (см. рис. 39)

- Option 1: Current Account at WIPO

$\checkmark$ Option 2: credit card payments

Credit card payments are available only for the payment of:

- registration fees (using eHague);

- renewal fees (using E-Renewal); or

- fees indicated on irregularity letters or other WIPO communications concerning international applications (using ePay).

Рисунок 39 - Вид экрана для перехода к сервисам оплаты пошлин по гиперссылкам

Следует отметить, что в случае доступа к сервису «E-Renewal» через опцию «credit card payments», оплата возможна только по кредитной карте.

Доступ к сервису «E-Renewal» можно также получить при выборе опции «Option 1: Current Account at WIPO» («Вариант 1: Текущий Счет в ВОИС») (см. рис. 39). После выбора данной опции откроется окно, показанное на рисунке 40, в котором нужно нажать на гиперссылку: «Learn more about the Current Account at WIPO» («Узнать больше о Текущем Счете в ВОИС»). 


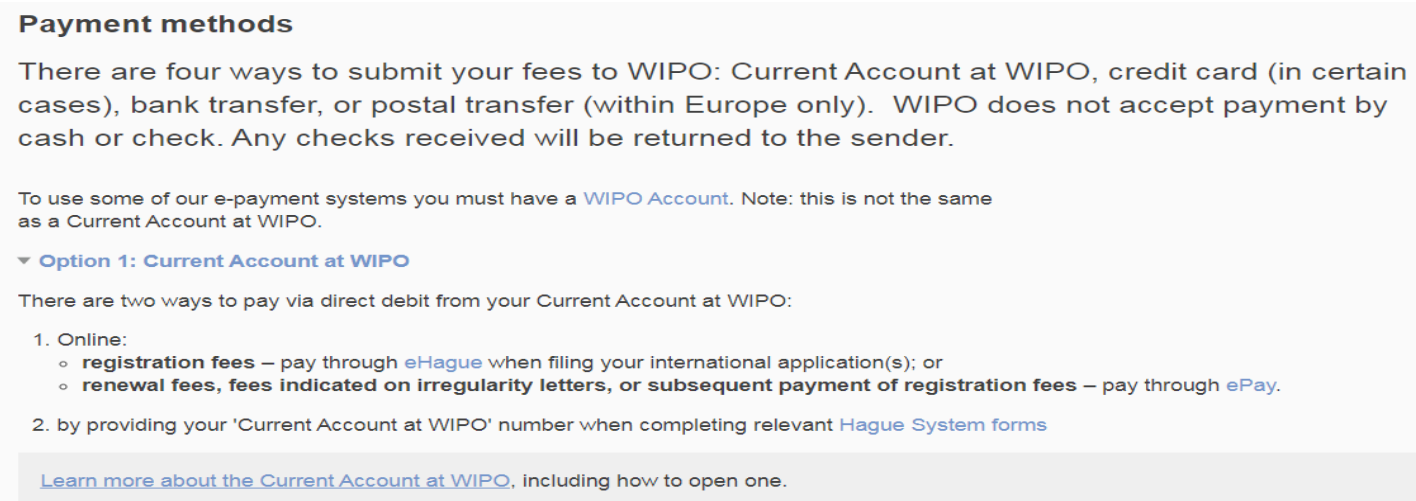

Рисунок 40 - Переход по гиперссылке «Learn more about the Current Account at WIPO» («Узнать больше о Текущем Счете в ВОИС»)

После нажатия на эту гиперссылку пользователь будет перенаправлен на информационную страницу о Текущем счете ВОИС (см. рис.41).

\section{Current Account at WIPO: Overview}

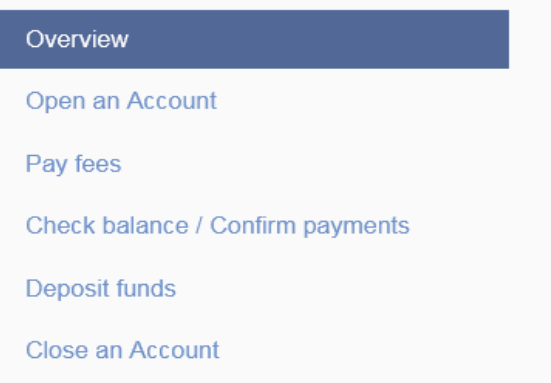

A Current Account at WIPO is a special financial account administered by WIPO. The account is managed in Swiss francs (CHF). To open and/or access a Current Account at WIPO, you need a WIPO Account.

\author{
Existing user? \\ Login to your Current Account portal \\ Warning - New authentication procedures as of November 1, 2018.
}

\section{Рисунок 41 - Информационная страница Current Account at WIPO}

После выбора опции Раy Fees откроется страница Current Account at WIPO How to Pay WIPO Fees (см. рис. 42), на которой из подраздела Наguе в разделе «1. Online, through our e-payment systems» можно перейти к сервису E-Renewal.

Для доступа к сервису необходимо быть зарегистрированным на сайте ВОИС пользователем. 


\section{Current Account at WIPO: How to Pay WIPO Fees}

Overview

Open an Account

Pay fees

Check balance / Confirm payments

Deposit funds

Close an Account
Please ensure that there are sufficient funds in your Current Account at WIPO before making a payment. Transactions that would result in a negative balance are not allowed.

There are three ways in which you can use your Current Account at WIPO to submit payments to WIPO:

\section{Online, through our e-payment systems}

Madrid, PCT and Hague Systems have dedicated e-payment systems. To use some of our e-payment systems you must create a WIPO account. Note: this is not the same as a WIPO Current Account at WIPO.

\begin{tabular}{|l|l|}
\hline Service & System(s) \\
\hline Madrid & $\begin{array}{l}\text { Online payment (7-10 digit WIPO reference number required) } \\
\text { Renewal } \\
\text { Subsequent Designation }\end{array}$ \\
\hline PCT & $\begin{array}{l}\text { EPCT (digital certificate required) } \\
\text { Payment platform (WIPO reference number required) }\end{array}$ \\
\hline Hague & $\begin{array}{l}\text { eHague } \\
\text { E-Renewal (international registration number required) } \\
\text { ePay (12 digit WIPO reference number required (EPAY-1234-5678)) }\end{array}$ \\
\hline
\end{tabular}

2. Indicate Current Account at WIPO as the preferred payment method on the relevant form

- Madrid System: select "Current Account at WIPO" on the Fee Calculation sheet attached to the relevant MM form.

- PCT System: select "Authorization to charge deposit or current account" on the Fee

Calculation sheet attached to the relevant PCT form.

- Hague System: complete Section 1 (Instruction to Debit from a Current Account at WIPO) of the Payment of Fees sheet attached to the relevant DM form

Рисунок 42 - Страница Current Account at WIPO How to Pay WIPO Fees 


\section{Заключение}

Главным результатом первого этапа НИР в соответствии с Техническим заданием и Календарным планом НИР являются аналитические материалы, полученные в ходе экспериментальных исследований функциональных возможностей электронных сервисов ВОИС, предназначенных для пользователей Гаагской системы международной регистрации промышленных образцов: «eHague», «E-Renewal» и «Е-Рау». Комплексное использование данных сервисов обеспечивает для заявителей осуществление в режиме онлай подачи международной заявки и различных ходатайств об изменении объема охраны, мониторинга делопроизводства по международной заявке, переписки с МБ ВОИС, оплаты пошлин, продления действия международных регистраций.

Полученные аналитические материалы, касающиеся функциональных возможностей электронных сервисов ВОИС подачи заявки, продления и оплаты пошлин, способов доступа к ним и приемов работы при их использовании, послужат основой для последующей разработки комплекса Руководств пользователя для российских заявителей.

Подготовленный в рамках первого этапа краткий обзор процедуры Гаагского соглашения может быть полезным для заявителей, впервые подающих международные заявки и не владеющих, в достаточной степени, правовыми основами международной процедуры, поэтому данный материал также будет использован при разработке Руководств пользователя, которые планируется разместить на сайте Роспатента.

Предполагается, что разработка комплекса Руководств пользователя электронными сервисами ВОИС для русскоязычной аудитории и их размещение на сайте Роспатента, позволит отечественным разработчикам дизайна активнее подавать заявки для получения охраны своих изделий на международном уровне. 


\section{Список использованных источников}

1. The Hague Agreement Concerning the International Registration of Industrial Designs, Geneva Act of July 2, 1999, [Электронный ресурс]: World Intellectual property organization: - URL: https://wipolex.wipo.int/en/text/285214, (дата обращения: 18.10.2021);

2. International Designs Bulletin [Электронный ресурс] - URL: https://www.wipo.int/haguebulletin/?locale=en (дата обращения: 23.08.2021).

3. Конвенция по охране промышленной собственности (Заключена в Париже 20.03.1883), (ред. от 02.10.1979), [Электронный ресурс] URL: http://www.consultant.ru/document/cons doc LAW 5111/, (дата обращения: 23.08.2021);

4. Common Regulations Under the 1999 Act and the 1960 Act of the Hague Agreement (as in force on January 1, 2014), [Электронный ресурс]: World Intellectual property organization: - URL: http://www.wipo.int/treaties/en/ text.jsp?file id=318753. (дата обращения: 18.10.2021);

5. Administrative Instructions for the Application of the Hague Agreement (as in force on January 1, 2019) [Электронный ресурс] - URL: https://www.wipo.int/export/sites/www/hague/en/legal texts/administrative instructions.p df (дата обращения: 23.08.2021);

6. WIPO IP Statistics Data Center [Electronic resourse] - URL: https://www3.wipo.int/ipstats/pmhindex.htm?tab=hague (дата обращения: 18.10.2021);

7. Hague Yearly Review 2019 [Electronic resourse]: World Intellectual property organization: - URL: https://www.wipo.int/edocs/pubdocs/en/ wipo pub 930 2021.pdf (дата обращения: 02.09.2021);

8. «Guidance on Preparing and Providing reproductions», [Electronic resourse] URL: https://www.wipo.int/export/sites/www/hague/en/how to/ pdf/guidance.pdf (дата обращения: 02.09.2021). 